Article

\title{
Intra-Community Scale Variability of Air Quality in the Center of a Megacity in South Korea: A High-Density Cost-Effective Sensor Network
}

\author{
Yongmi Park ${ }^{1} \mathbb{D}$, Ho-Seon Park ${ }^{1}$, Subin Han ${ }^{1}$, Kyucheol Hwang ${ }^{1}$, Seunghyun Lee ${ }^{1}$, Jin-Young Choi ${ }^{2}$, \\ Jae-Bum Lee ${ }^{2}$, Sang-Hyun Lee ${ }^{3}{ }^{\mathbb{D}}$, Kyung-Hwan Kwak ${ }^{4}{ }^{\mathbb{D}}$, Jae-Jin Kim ${ }^{5}$ and Wonsik Choi ${ }^{5, *}$
}

1 Department of Earth Environmental System Science, Pukyong National University, Busan 48547, Korea; ygm23@pukyong.ac.kr (Y.P.); phs1549@pukyong.ac.kr (H.-S.P.); sbhan@pukyong.ac.kr (S.H.); ssife@kiost.ac.kr (K.H.); wwwhyun96@pukyong.ac.kr (S.L.)

2 Climate and Air Quality Research Department, National Institute of Environmental Research, Incheon 22689, Korea; jychoi1122@korea.kr (J.-Y.C.); gercljb@korea.kr (J.-B.L.)

3 Department of Atmospheric Sciences, Kongju National University, Gongju-si 32588, Korea; sanghyun@kongju.ac.kr

4 School of Natural Resources and Environmental Science, Kangwon National University, Chuncheon-si 24341, Korea; khkwak@kangwon.ac.kr

5 Department of Environmental Atmospheric Science, Pukyong National University, Busan 48547, Korea; jjkim@pknu.ac.kr

* Correspondence: wschoi@pknu.ac.kr

check for updates

Citation: Park, Y.; Park, H.-S.; Han, S.; Hwang, K.; Lee, S.; Choi, J.-Y.; Lee, J.-B.; Lee, S.-H.; Kwak, K.-H.; Kim, J.-J.; et al. Intra-Community Scale Variability of Air Quality in the Center of a Megacity in South Korea: A High-Density Cost-Effective Sensor Network. Appl. Sci. 2021, 11, 9105. https://doi.org/10.3390/app11199105

Academic Editor: Elza Bontempi

Received: 31 August 2021

Accepted: 27 September 2021

Published: 30 September 2021

Publisher's Note: MDPI stays neutral with regard to jurisdictional claims in published maps and institutional affiliations.

Copyright: (c) 2021 by the authors. Licensee MDPI, Basel, Switzerland. This article is an open access article distributed under the terms and conditions of the Creative Commons Attribution (CC BY) license (https:// creativecommons.org/licenses/by/ $4.0 /)$.

\begin{abstract}
To investigate the spatial and temporal variability of air quality $\left(\mathrm{CO}, \mathrm{NO}_{2}, \mathrm{O}_{3}\right.$, and $\left.\mathrm{PM}_{2.5}\right)$ with a high spatial resolution in various adjacent micro-environments, 30 sets of sensor-nodes were deployed within an $800 \times 800 \mathrm{~m}$ monitoring domain in the center of the largest megacity (Seoul) in South Korea. The sensor network was operated in summer and winter. The daily variation in air pollutant concentrations revealed a similar trend, with discernible concentration differences among monitoring sub-sites and a government-operated air quality monitoring station. These differences in pollutant levels (except $\mathrm{PM}_{2.5}$ ) among the sub-sites were pronounced in the daytime with high volumes of traffic. The coefficient of divergence and Pearson correlation coefficient showed that spatial and temporal variability was more significant in summer than winter. Ozone displayed the greatest spatial variability, with little temporal variability among the sub-sites and a negative correlation with $\mathrm{NO}_{2}$, implying that ozone concentrations were primarily determined by vehicular $\mathrm{NO}_{X}$ emissions due to NO titration effects under the urban canopy. The $\mathrm{PM}_{2.5}$ concentration displayed homogeneous spatial and temporal distributions over the entire monitoring period, implying that $\mathrm{PM}_{2.5}$ monitoring with at least a $1 \times 1 \mathrm{~km}$ resolution is sufficient to examine the spatial and temporal heterogeneity in urban areas.
\end{abstract}

Keywords: low-cost sensors; dense air quality monitoring; intra-community air quality; air quality sensor network; spatial heterogeneity

\section{Introduction}

Traffic emissions are the major source of air pollution in urban areas [1], accounting for $90 \%$ of primary pollutant emissions (e.g., $\mathrm{NO}_{X}$ and $\mathrm{CO}$ ) in Korea [2]. Populations living near major roadways have a high risk of acute and chronic health problems due to air pollution exposure [3-5]. The population living in urban areas accounted for $56 \%$ of the global population in 2020, which is expected to increase to up to $68 \%$ in 2050 worldwide (the proportion of the urban population was $82 \%$ in high-income countries (including Korea) in 2020) [6]. Thus, it is important to assess the health risks associated with being exposed to air pollutants emitted from dense urban road-networks by monitoring the highly spatiotemporally resolved air quality in various urban micro-environments. 
The air pollutant concentrations in urban areas vary spatially and temporally due to the urban configuration, complicated dense road networks, fleet composition, meteorological conditions, and other factors [7-9]. The wind fields and dispersion characteristics of the in-canopy atmosphere are modified by the urban built environment, which alters the ventilation capacity and dilution of local emissions, ultimately enhancing or mitigating local concentrations of air pollutants close to sources $[7,10]$. It has previously been reported that the higher the traffic density, the less turbulent energy is produced, which affects the capacity for pollutant dispersion [9]. Consequently, complicated urban canopy environments can lead to spatiotemporally heterogeneous distributions of traffic-related air pollutants. This heterogeneity of pollutant distribution causes the extent of pedestrian exposure to air pollutants to vary over time and space. Therefore, spatiotemporally dense air quality monitoring is required, particularly in the center of urban areas, to assess the complicated built environment, dense road-network, and large volume of people moving through the city.

Many studies have investigated the spatial distributions of traffic-related air pollutants based on model simulations with computational fluid dynamics (CFD, [11]) and large eddy simulation (LES, [12]), together with observations made from a mobile platform [10,13]. Mobile measurements provide highly spatially resolved air pollutant distributions; however, simultaneous and continuous monitoring at various locations is limited and on-road measurements can be influenced by intermittently encountered high-emitting vehicles [14]. Many CFD or LES modeling studies of urban micro-environments have targeted an idealized street canyon, while studies of real urban environments at larger spatial scales are relatively rare. In addition, model validation with observations from multiple stations or mobile platforms is not simple because model results represent the typical distributions in certain specific environments, whereas real atmospheric and traffic conditions vary over relatively short periods.

To overcome those limitations modeling and mobile measurement studies contain, several recent studies have attempted to build a highly spatially resolved air quality monitoring network, using a number of low-cost sensors in urban areas [15-20]. One study deployed 35 low-cost sensors in a $10 \times 10 \mathrm{~km}$ domain in Cambridge, UK to monitor CO, NO, and $\mathrm{NO}_{2}$, showing the potential of a low-cost sensor network for gaseous pollutants [19]. Another study used 32 sensor-nodes $\left(\mathrm{CO}, \mathrm{NO}\right.$, and $\left.\mathrm{NO}_{2}\right)$ that were deployed in and around the city of Cambridge, UK, with a particular focus on the spatial distribution of $\mathrm{CO}$ between urban and rural areas [17]. To investigate the spatial heterogeneity of particulate matter (PM), a previous study deployed 17 sets of PM sensors in Memphis, USA [16]. Another study deployed 11 sensor-nodes to monitor $\mathrm{CO}_{2}$ and $\mathrm{PM}$ within a $1.8 \times 1 \mathrm{~km}$ spatial domain, to examine local emission sources [18]. Although these studies have shown the great potential of sensor networks for high-density air quality monitoring, their spatial resolution (city scale) was too large to examine intra-community scale variability and the target air pollutants were limited to a few primary gases or PM. Thus, more integrated air quality monitoring, including various gaseous and particulate pollutants with a sensor network on the intra-community scale, is still rare.

In a previous study, the profiles of traffic-related pollutants were reconstructed at various distances from major roadways in different urban environments [21]. The results showed that the concentrations of traffic-related pollutants decreased sharply within $150-400 \mathrm{~m}$ of a road during the daytime [21]. Thus, the monitoring of various traffic-related air pollutants at a high spatial resolution is required, particularly in the urban center with its dense road network, large volumes of traffic, and complicated built environments. In this study, 30 sets of air quality sensor-nodes (for gaseous and particulate pollutants: $\mathrm{CO}, \mathrm{NO}_{2}$, $\mathrm{O}_{3}$, and $\mathrm{PM}_{2.5}$ ) were deployed in an $800 \times 800 \mathrm{~m}$ monitoring domain in the center of Seoul, the largest megacity in Korea. The monitoring site consisted of four microenvironments with distinctly different traffic and built environments. This study aims to understand the heterogeneity of air pollutant distributions in space and time on the intra-community scale 
and to suggest the spatial resolution adequate for traffic-related air pollutants monitoring in urban areas.

\section{Methods}

To investigate the characteristics of air pollutant distributions in various urban microenvironments, we built a high-density air quality monitoring network consisting of 30 sets of sensor-nodes in an $800 \times 800 \mathrm{~m}$ spatial domain. Intra-community air quality with a sensor network was monitored for two weeks under two distinctly different weather conditions (a humid and hot summer and dry and cold winter) in 2017 (25-31 August) and 2018 (9-22 January).

\subsection{Monitoring Site and Spatially Dense Air Quality Monitoring Network}

An area with a domain size of $800 \times 800 \mathrm{~m}$ around Seoul City Hall was selected as the monitoring site $\left(37.56665^{\circ} \mathrm{N} / 126.97858^{\circ} \mathrm{E}\right)$. The area was located in the center of Seoul, with a dense road network (a major source of air pollutants in cities), and contained various urban micro-environments, including an urban street canyon, mixture of high- and low-rise buildings, and open spaces with limited traffic flows (Figure 1; Table 1). In addition, an air quality monitoring station (AQMS) operated by the government (the Institute of Health and Environment, Seoul) was located within the monitoring domain, and two automatic weather stations (AWS) operated by the Korea Meteorological Administration (KMA) were located $\sim 1 \mathrm{~km}$ west and east of the domain, respectively (Figure 1).
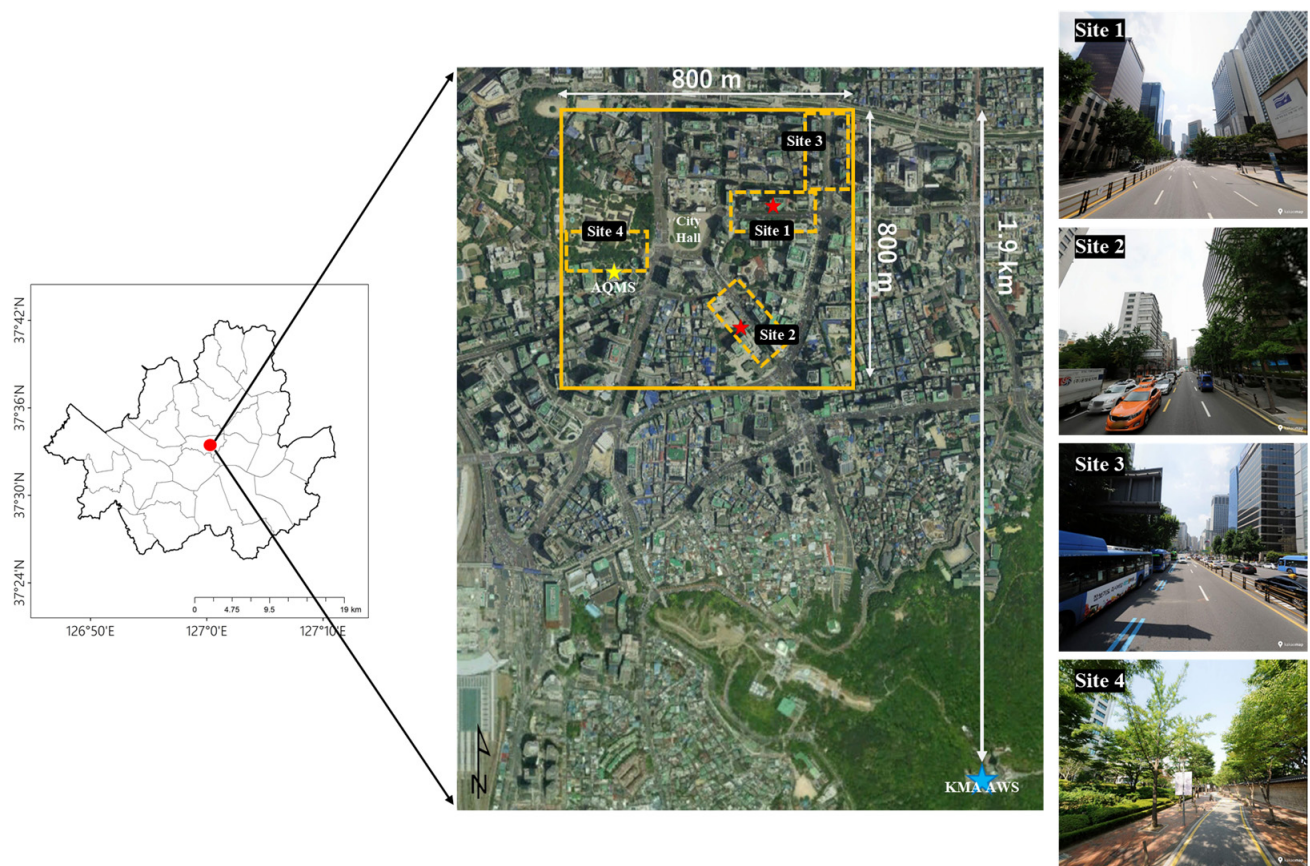

Figure 1. Map of the sensor network monitoring domain. Yellow dashed-lined rectangles represent the micro-environments (sub-sites) where sensor-nodes were installed (4-8 sensor-nodes for each site). Red stars represent the locations of the portable AWS on the ground (Site- 1 in summer and Site- 2 in winter) and the sky-blue star denotes the location of the AWS operated by the Korea Meteorological Administration (KMA). The yellow circle represents the location of Jung-gu AQMS, operated by the government.

To examine the spatial distributions of air pollutants in various urban micro-environments, we placed sensor-nodes along the roadside of four distinct micro-built environments: an urban street canyon (Site-1; Eulji-ro) with a seven-lane road; a dense mixture of mediumsized low-rise buildings on both sides of a relatively narrow five-lane road with some open spaces (parking lots) (Site-2; Sogong-ro); a mixture of tall and medium-sized buildings 
along both sides of a wide eight-lane road with a large traffic flow (Site-3; Namdaemun-ro); and a road with medium-sized buildings along one side and open space on the other side with limited traffic flow (Site-4; Deogsugung-gil). Further details of the characteristics of these micro-environments are provided in Table 1.

Table 1. Characteristics of the traffic flows and built environments of the monitoring sub-sites.

\begin{tabular}{|c|c|c|c|c|}
\hline $\begin{array}{c}\text { Qualitative } \\
\text { Characteristics }\end{array}$ & $\begin{array}{c}\text { Site-1 } \\
\text { (Eulji-ro) }\end{array}$ & $\begin{array}{c}\text { Site-2 } \\
\text { (Sogong-ro) }\end{array}$ & $\begin{array}{c}\text { Site-3 } \\
\text { (Namdaemun-ro) }\end{array}$ & $\begin{array}{c}\text { Site-4 } \\
\text { (Deogsugung-gil) }\end{array}$ \\
\hline $\begin{array}{c}\text { Surrounding } \\
\text { built environments }\end{array}$ & $\begin{array}{l}\text { Typical urban canyon } \\
\text { surrounded by tall } \\
\text { buildings on both sides of } \\
\text { the road }\end{array}$ & $\begin{array}{c}\text { Large open lot and } \\
\text { moderate buildings } \\
\text { between several large } \\
\text { buildings }\end{array}$ & $\begin{array}{l}\text { Tall buildings on both } \\
\text { sides of the road with } \\
\text { the open space and } \\
\text { small buildings } \\
\text { between tall } \\
\text { buildings }\end{array}$ & $\begin{array}{l}\text { Pedestrian-oriented } \\
\text { one lane road. } \\
\text { Medium sized } \\
\text { building on one side } \\
\text { and empty lot on the } \\
\text { other side }\end{array}$ \\
\hline $\begin{array}{c}\text { Traffic } \\
\text { (Daytime traffic volume } \\
\text { for 10:00-18:00) }\end{array}$ & $\begin{array}{l}\text { Heavy traffic (predominant } \\
\text { in the direction to the city } \\
\text { hall-westbound). Due to } \\
\text { access to the largest } \\
\text { department store and hotel, } \\
\text { slower vehicle speeds } \\
\left(21,740 \text { veh } 8-h^{-1}\right)\end{array}$ & $\begin{array}{l}\text { Moderate traffic. } \\
\text { Due to narrow road } \\
\text { width, frequent } \\
\text { daytime traffic jam } \\
\text { occurs }(16,867 \\
\left.\text { veh } \cdot 8-\mathrm{h}^{-1}\right)\end{array}$ & $\begin{array}{c}\text { Heavy traffic } \\
\text { distributed equally in } \\
\text { both directions (due } \\
\text { to wide road width, } \\
\text { higher vehicle } \\
\text { speeds) } \\
\left(19,972 \text { veh } 8-\mathrm{h}^{-1}\right)\end{array}$ & $\begin{array}{l}\text { No vehicle access } \\
\text { from 11:00 to 13:00. } \\
\text { Traffic is minimal on } \\
\text { the } \\
\text { pedestrian-oriented } \\
\text { one-lane road (-) }\end{array}$ \\
\hline $\begin{array}{l}\text { Road width (m) } \\
\text { /Number of lanes }\end{array}$ & $\sim 35 / 7$ & $\sim 19 / 5$ & $\sim 42 / 8$ & $\sim 13 / 1$ \\
\hline Mean building height (m) & 53.8 & 32.3 & 22.0 & 13.0 \\
\hline $\begin{array}{l}\text { Building } \\
\text { area-weighted } \\
\text { building } \\
\text { height }^{2}(\mathrm{~m})\end{array}$ & 99.2 & 22.7 & 38.4 & 23.8 \\
\hline $\begin{array}{l}\text { Monitoring } \\
\text { period }\end{array}$ & \multicolumn{2}{|c|}{$\begin{array}{l}\text { 25-31 August } 2017 \\
\text { 9-22 January } 2018\end{array}$} & $\stackrel{-}{\text { 9-22 January } 2018}$ & $\begin{array}{l}\text { 25-31 August } 2017 \\
\text { 9-22 January } 2018\end{array}$ \\
\hline
\end{tabular}

${ }^{1}$ Road width including set-back distance. ${ }^{2} \sum$ (building area $\times$ building height) $/ \sum$ (building area).

Sensor-nodes were installed on lampposts at a height of $\sim 2.5 \mathrm{~m}$ above the ground along the roadsides. The distance between the sensor-nodes was about $20-40 \mathrm{~m}$ in each micro-environment. In addition, to examine the differences in air pollutant concentrations between both sides of the road due to the modified in-canopy wind flows (e.g., in-canopy circulation in an urban street canyon; [22]), we installed pairs of sensor-nodes facing each other alongside the roadside (Supplementary Information (SI), Figure S1). We also determined the vertical distributions of air pollutants by placing two sensor-nodes on the roofs of the tallest building (132 $\mathrm{m}$ a.g.l.) and an attached fourth-floor building ( 15 $\mathrm{m}$ a.g.l.) in the street canyon site (Site-1).

\subsection{Sensor-Nodes and Data Quality}

The sensor-nodes contained cost-effective sensors for air pollutants $\left(\mathrm{O}_{3}, \mathrm{NO}_{2}, \mathrm{CO}\right.$, $\mathrm{PM}_{2.5}$, and $\mathrm{PM}_{10}$ ), a weather sensor (temperature and humidity), and a fan for ventilation (ventilation rate $>20$ times the volume per minute) [23]. The details and specifications of the sensors incorporated in the sensor-node are shown in our previous study (Table 1 in Park et al. [23]). $\mathrm{CO}$ (CO-B4, Alphasense) and $\mathrm{O}_{3}$ (SM50, Aeroqual) sensors are based on an electrochemical technique, and the working principle is described in detail in Mead et al. [19]. The $\mathrm{NO}_{2}$ sensor (MiCS-2714, SGX Sensortech) is a semiconducting metal oxide sensor that measures changes in electrical conductivity [24]. The PM sensor (PMS5003, Plantower) uses a light scattering technique, and a detailed working principle is described in Zheng et al. [25]. The sensor-nodes stored data at 10-s intervals on an SD card and communicated with a smartphone via Wi-Fi to display the sensor conditions, pollutant concentrations, and battery levels. A lead-acid battery was used to power the sensor-nodes, and the battery was periodically replaced due to the lack of a power supply in the streets. Further details of the sensor-node configuration are provided in our previous study [23]. 
To build an air quality monitoring network with a large number of sensors, there is a need to quantitatively evaluate the consistency and accuracy of sensor readings for spatial assessment of air pollutants. We conducted intercomparisons by placing the 30 sensor-nodes in the same location (Pukyong National University campus) for 2-4 days before and after the field surveys, in both the summer and winter (under real atmospheric conditions). The readings from the 30 sensor-nodes exhibited high consistency $\left(\mathrm{R}^{2}>0.90\right.$; Table 3 in Park et al. [23]) and the linearity between sensor readings did not change before and after the field surveys (Supplementary Information Figure S2) [23]. We corrected the sensor readings from 29 sensor-nodes to those of the reference sensor node (i.e., the sensor node located nearest to the AQMS inlet) (1st step correction).

To assure the accuracy of sensor readings, we placed the reference sensor-node in close proximity to the inlet of an AQMS (Jongro-gu AQMS located $2 \mathrm{~km}$ east of the monitoring site) during the summer and winter field intensive periods and conducted intercomparison tests between the reference sensor node and federal reference/equivalent method (FRM/FEM) instruments. For all air pollutants (except $\mathrm{NO}_{2}$ ), the sensor-node revealed a strong linear consistency with the FRM/FEM instruments for both the summer and winter experimental periods $\left(R^{2} \geq 0.80\right.$; Table 4 in Park et al. [23]). Thus, based on these intercomparison results, we corrected the data from the 29 sensor-nodes, which had been initially corrected to correspond to the reference sensor readings, and now corresponded to the officially validated concentrations from the FRM/FEM instruments (2nd step correction, Supplementary Information Figure S3) [23]. The $\mathrm{NO}_{2}$ sensors appeared to be sensitive to weather conditions and potential interferences (e.g., $\mathrm{O}_{3}$ ). We therefore additionally corrected $\mathrm{NO}_{2}$ sensor readings with a multi-variate regression method using $\mathrm{O}_{3}$, temperature, and humidity as explanatory variables [23]. More details about sensor evaluation and data correction are provided in our previous study [23]. Finally, the corrected air pollutant concentrations from the sensor-nodes agreed well with those of the FRM/FEM instruments at Jongro-gu AQMS (Figure S3). We compared the corrected air pollutant concentrations to those obtained from a nearby AQMS located within the monitoring site (Jung-gu AQMS), and found good consistency between the two datasets, considering that the sensor-node and Jung-gu AQMS were separated by $\sim 30 \mathrm{~m}$ horizontally and $\sim 15 \mathrm{~m}$ vertically $(2.5 \mathrm{~m}$ a.g.l. for the sensor node vs. $\sim 17.5 \mathrm{~m}$ a.g.l. for the AQMS inlet) (Figure 1).

Although the $\mathrm{PM}$ sensor provides $\mathrm{PM}_{1}, \mathrm{PM}_{2.5}$, and $\mathrm{PM}_{10}$ signals, we omitted $\mathrm{PM}_{1}$ and $\mathrm{PM}_{10}$ in our analyses and discussion because we were not able to evaluate and correct the sensor's $\mathrm{PM}_{1}$ signals due to the absence of an accurate reference instrument. In addition, the intercomparison tests for $\mathrm{PM}_{10}$ between the sensor and the FEM instrument did not provide reliable results, particularly in summer when $\mathrm{PM}_{2.5} / \mathrm{PM}_{10}$ ratios were low [23]. Indeed, $\mathrm{PM}_{10}$ readings varied in almost the same way with $\mathrm{PM}_{2.5}$ (not shown here) for the entire monitoring period because the PM sensor appears to allocate $\mathrm{PM}_{2.5}$ and $\mathrm{PM}_{10}$ based on an algorithm not explicitly described [26].

\subsection{Other Observation Data}

Heterogeneity in vehicular emissions due to the variation of traffic environments is one of the major factors controlling air pollutant distributions in micro-built environments within populated urban areas. We, therefore, recorded traffic on the main roads with two video cameras, to obtain detailed traffic information. The traffic information obtained from video clips included traffic flow rates and fleet composition (categorized into seven types depending on size and fuel-type: passenger cars (gasoline), passenger sport utility vehicles (SUVs, diesel), taxis (liquid petroleum gas: LPG), public buses (compressed natural gas: $\mathrm{CNG}$ ), commercial buses (diesel), heavy-duty trucks (diesel), and motorcycles (gasoline)).

To investigate the effect of building-induced wind on air pollutant distributions, we placed a portable AWS on the ground during the monitoring periods (at Site- 1 in summer and Site-2 in winter). To determine the prevailing winds over the urban canopy, we also collected meteorological data from two nearby AWSs operated by KMA. Hourly air quality data not directly affected by emission sources in the monitoring domain were obtained 
from the Jung-gu AQMS maintained by Seoul Research Institute of Public Health and Environment. The AQMS was located on the roof of a four-story building ( 15 m a.g.1.) located next to Deoksu Palace and a small, pedestrianized street (Figure 1).

\section{Results and Discussion}

\subsection{Meteorology and Air Quality}

The daily meteorology data are presented in Table S1 (Supplementary Information). During the summer monitoring period, a rainfall event occurred once (28 August 2017, 18:00-21:00) and there was an intensive rainfall event two days before monitoring began (23 August 2017). Temperature ranged from 15.4 to $30.4{ }^{\circ} \mathrm{C}$, with a mean of $21.2 \pm 3.3^{\circ} \mathrm{C}$, and the mean wind speed was $1.8 \pm 1.3 \mathrm{~m} \cdot \mathrm{s}^{-1}$ (maximum of $7.8 \mathrm{~m} \cdot \mathrm{s}^{-1}$ ) (data from the KMA AWS, $267 \mathrm{~m}$ a.s.l.). The mean wind speed on the ground (Site-1: street canyon, $1.8 \mathrm{~m}$ a.g.1.) was $0.6 \pm 0.3 \mathrm{~m} \cdot \mathrm{s}^{-1}$ (Table 2).

Table 2. Characteristics of the meteorology during the monitoring period (standard deviations are given in parentheses).

\begin{tabular}{cccccc}
\hline \multirow{2}{*}{ Pummer } & Period & $\begin{array}{c}\text { Temperature } \\
\left({ }^{\circ} \mathbf{C}\right)\end{array}$ & $\begin{array}{c}\text { Relative } \\
\text { Humidity (\%) }\end{array}$ & $\begin{array}{c}\text { Wind Speed } \\
\left(\mathbf{m} \cdot \mathbf{s}^{-\mathbf{1})}\right.\end{array}$ \\
\hline \multirow{2}{*}{ Winter } & Upper & 25-31 August 2017 & $21.2(3.3)$ & $/$ & $1.8(1.3)$ \\
& Ground & 26-31 August 2017 & $23.4(3.2)$ & $49.1(13.8)$ & $0.6(0.3)$ \\
\hline & Ground & 09-22 January 2018 & $-2.3(5.7)$ & $/$ & $2.3(1.4)$ \\
10-18 January 2018 & $-1.0(6.4)$ & $53.0(14.2)$ & $1.1(0.8)$ \\
\hline
\end{tabular}

The prevailing winds were north- or south-westerlies in the daytime, and northerlies or easterlies at night (representing a weak sea-breeze; Supplementary Information Figure S4). The ground wind direction tended to be similar to that of the prevailing winds, likely because the prevailing wind direction coincided with the orientation of the roadway in the street canyon and was also influenced by street canyon effects (Site-1). However, ground wind speeds were minimal when the prevailing winds were easterlies (Figure 1).

During the winter monitoring period, a strong cold wave with intense snowfall occurred the day before the winter observation (8 January 2018), and a few snow events also occurred during the monitoring period (13:00-17:00 on 9 January 20:00-24:00 on 12 January and 04:00-08:00 on 22 January 2018). Temperature ranged from -16.2 to $7.4{ }^{\circ} \mathrm{C}$ (avg. $-2.3 \pm 5.7^{\circ} \mathrm{C}$ ), and the mean wind speed was $2.3 \pm 1.4 \mathrm{~m} \cdot \mathrm{s}^{-1}$ (max. wind speed: $10.3 \mathrm{~m} \cdot \mathrm{s}^{-1}$ ) from KMA AWS (prevailing winds). The mean ground-level wind speed observed at Site- 2 was $1.1 \pm 0.8 \mathrm{~m} \cdot \mathrm{s}^{-1}, 48 \%$ weaker than that of the prevailing winds. The prevailing winds were westerly or easterly, whereas the ground-level winds were northerlies when the prevailing winds were westerly, and a mixture of south- or northeasterly with weak wind speeds $\left(<1 \mathrm{~m} \cdot \mathrm{s}^{-1}\right)$ when the prevailing winds were easterly, likely due to blocking effects by the surrounding tall buildings (Figure 1).

In both the summer and winter periods, ground-level air temperature was somewhat higher than at the KMA AWS location ( 1.4 and $0.9 \mathrm{~km}$ south of the ground AWS locations in the summer and winter, respectively). The higher ground-level temperature in the city could be caused by the differences in land-use (paved roads vs. the foot of Nam Mountain) and/or heat-release from surrounding buildings. However, we cannot exclude the possibility of systematic differences between temperature sensors, because the 1:1 plots had a slope close to one, with an off-set $\left(\sim 3.9^{\circ} \mathrm{C}\right.$ ) (Figure $\left.2 \mathrm{c}, \mathrm{f}\right)$. When the prevailing winds were westerlies, ground-level wind speeds were $\sim 26 \%$ (summer) and $\sim 46 \%$ (winter) weaker than that of the prevailing winds due to surface stress (friction) and displacement height of the urban canopy. However, consistent weak ground wind speeds $\left(<1 \mathrm{~m} \cdot \mathrm{s}^{-1}\right)$ occurred when the prevailing winds were easterlies, regardless of their speeds or the locations of ground AWS (Figure 2b,e). We cannot explain the suppressed wind speeds for the easterly prevailing winds, although they could be due to geographic characteristics, but suppressed 
ground wind speeds could affect the local air quality by hindering the ventilation/dilution of emissions from the roadways.

\section{Summer}
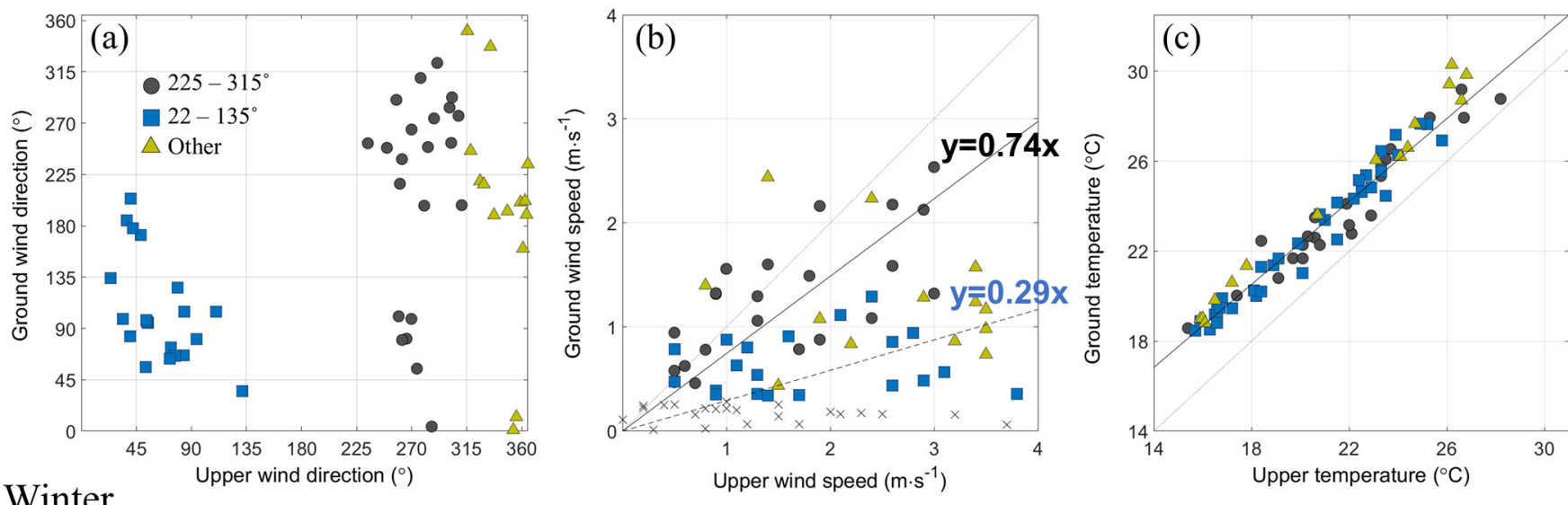

Winter

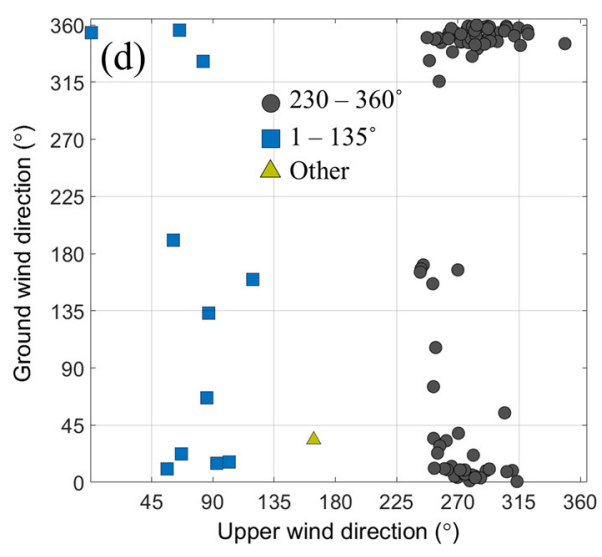

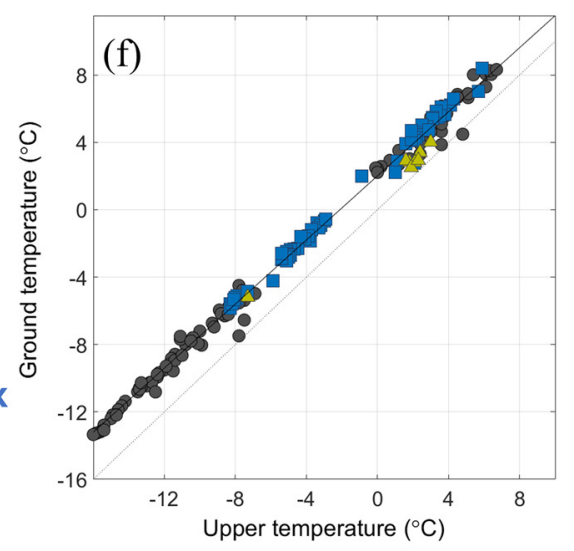

Figure 2. Comparison of the hourly meteorology between the KMA AWS site (prevailing wind) and ground level (Site-1 in summer and Site-2 in winter). (a,d) show wind direction, $(\mathbf{b}, \mathbf{e})$ wind speed, and $(\mathbf{c}, \mathbf{f})$ the temperature in summer and winter, respectively. Black circles denote westerly prevailing winds, blue squares easterlies, and yellow triangles other directions. The gray $x$ indicates that ground wind speeds were less than $0.3 \mathrm{~m} \cdot \mathrm{s}^{-1}$ (wind direction could not be determined). The black solid and gray dotted lines in $(\mathbf{b}, \mathbf{e})$ represent the linear fits for the black circles and blue squares, respectively.

As expected, the concentrations of traffic-related primary pollutants $\left(\mathrm{CO}\right.$ and $\left.\mathrm{NO}_{2}\right)$ decreased sharply as wind speeds increased in both summer and winter. The decreasing rates as a function of wind speed were larger and more prominent for the ground wind speed than the prevailing wind speeds (Figure $3 a, b, e, f)$. When the ground wind speed exceeded $2 \mathrm{~m} \cdot \mathrm{s}^{-1}$, the primary pollutant concentration reached the urban background level in this area (Figure 3e,f). Ozone concentrations increased with wind speed because, under calm conditions, high $\mathrm{NO}$ levels would be expected, as shown by the $\mathrm{NO}_{2}$ measurements (Figure $3 \mathrm{~b}, \mathrm{f}$ ), so the abundant $\mathrm{NO}$ could effectively remove ozone under the urban canopy. The $\mathrm{PM}_{2.5}$ concentrations displayed a similar trend to that of the primary gaseous pollutants because the accumulation of precursor gases under calm conditions favors secondary $\mathrm{PM}_{2.5}$ production, and $\mathrm{PM}_{2.5}$ is not affected by chemical loss processes unlike ozone $[27,28]$. 

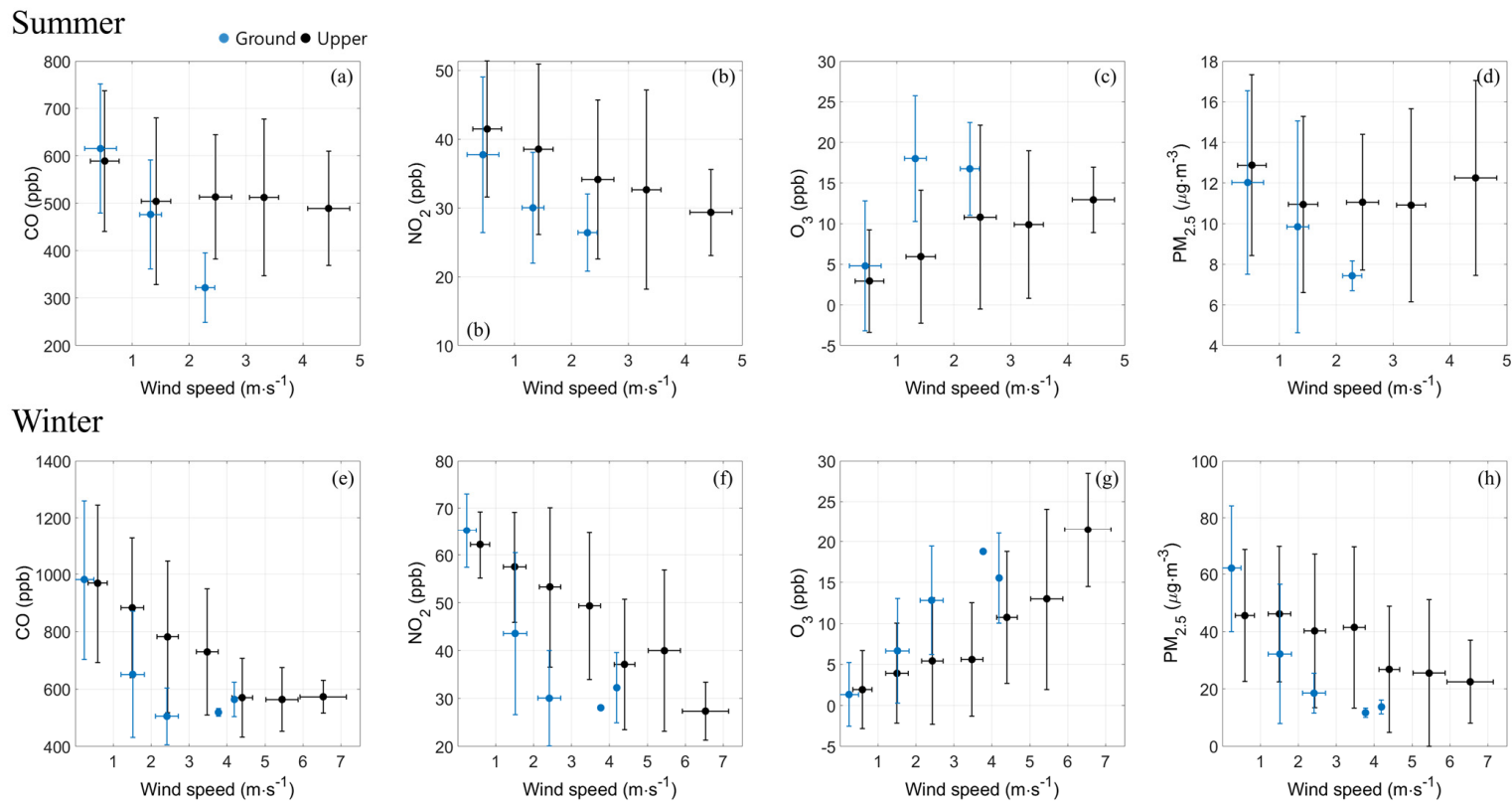

Figure 3. Air pollutant concentrations (at Site -1 in summer and Site -2 in winter) as a function of wind speed (blue circles: ground wind speed; black circles: prevailing wind speed). Error bars denote standard deviations. (a-d) $\mathrm{CO}, \mathrm{NO}_{2}, \mathrm{O}_{3}$, and $\mathrm{PM}_{2.5}$ in summer (at Site-1), (e-h) $\mathrm{CO}, \mathrm{NO}_{2}, \mathrm{O}_{3}$, and $\mathrm{PM}_{2.5}$ in winter (at Site-2).

\subsection{Traffic}

For the summer period, the weekday traffic volume in Site- 1 was slightly higher than that of the weekend (mean weekday traffic $=1352$ vehicles $\cdot(30 \mathrm{~min})^{-1}$ vs. mean weekend traffic $=1061$ vehicles $\left.\cdot(30 \mathrm{~min})^{-1}\right)$. The total traffic volume at Site- 2 was lower than at Site-1 $\left(\right.$ weekday $=1041$ vehicles $\left.\cdot(30 \mathrm{~min})^{-1}\right)$, but due to the narrow road width (Table 1$)$, frequent congestion occurred during the daytime. Winter traffic volumes at Site- 1 and Site-2 were similar to those in summer. At Site-3, weekday and weekend traffic volumes were similar, with a mean of 1199 and 1046 vehicles. $(30 \mathrm{~min})^{-1}$, respectively (Figure 4a). Site-4 had minimal traffic, with no traffic access from 11:00 to 13:00. Thus, no traffic record was obtained for this pedestrianized street.

(a)
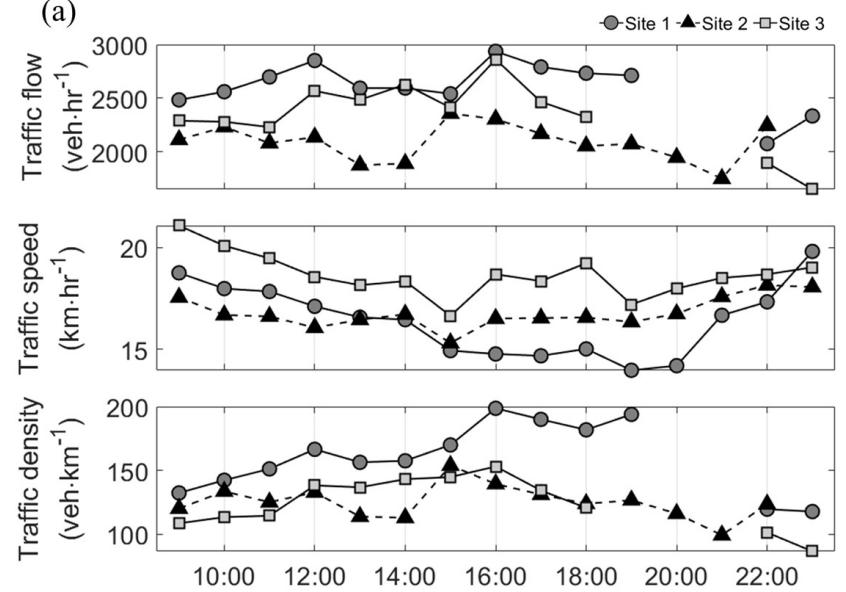

(b)

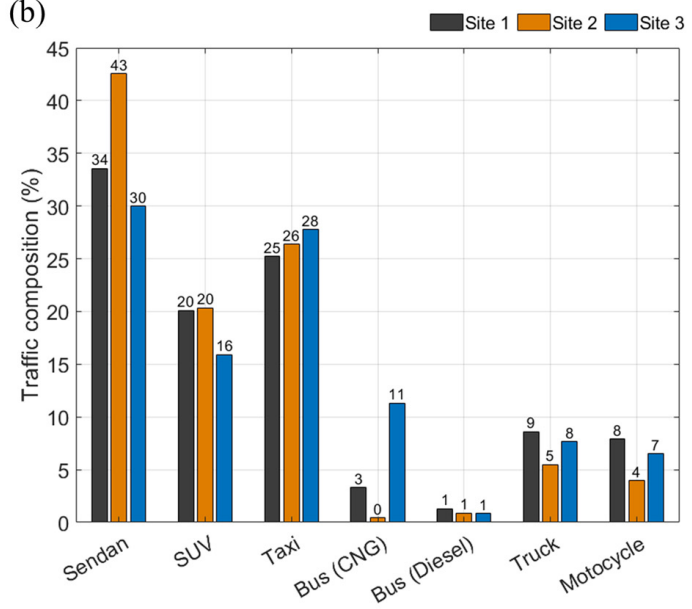

Figure 4. Weekday traffic characteristics at three sub-sites for the entire monitoring period. (a) Diurnal variations in the traffic flow rate (top), mean vehicle speed (middle), and traffic density (bottom; i.e., traffic flow rate divided by traffic speed). Dark gray circles represent Site-1, black triangles represent Site-2, and gray squares represent Site-3 (winter only). (b) Mean fleet composition (\%) at each sub-site (traffic speed is provided by Transport Operation \& Information Service managed by Seoul; https:/ / topis.seoul.go.kr/refRoom/openRefRoom_1.do (accessed on 23 June 2021)). 
The major constituents of the traffic flow at all monitoring sites were sedans (gasoline) (32-42\%), taxis (LNG) (24-27\%), and SUVs (diesel) (17-23\%), accounting for 76-84\% of the total traffic. Diesel trucks and motorcycles accounted for 5-6\% of the traffic flow at all monitoring sites. There was a meaningful volume of public buses (CNG) only at Site- 4 (11\%) (Figure $4 \mathrm{~b})$.

\subsection{Temporal Variations of Air Pollutants in the Various Micro-Environments \\ 3.3.1. Daily Variations}

In the summer monitoring period, weather conditions were consistent except on 28 August 2017, when it rained in the evening. The first 4 days of the winter monitoring period were impacted by a cold wave, with consistently low concentrations of air pollutants (cold wave case). Following the cold wave event, the $\mathrm{PM}_{2.5}$ concentration increased sharply from the evening of 13 January 2018, and a severe $\mathrm{PM}_{2.5}$ pollution event with a daily mean concentration of $76 \mu \mathrm{g} \cdot \mathrm{m}^{-3}$ occurred during 16-17 January 2018 (PM pollution case) (Figure 5h).

As expected, the air pollutant levels were higher in winter (except for the cold wave period), with a wider temporal variation than in the summer season (Figure 5). In summer, the daily mean concentrations of $\mathrm{CO}, \mathrm{NO}_{2}$, and $\mathrm{PM}_{2.5}$ ranged from 370 to $780 \mathrm{ppb}, 10$ to $52 \mathrm{ppb}$, and 8 to $17 \mu \mathrm{g} \cdot \mathrm{m}^{-3}$, respectively, whereas in winter they ranged from 400 to $1370 \mathrm{ppb}, 20$ to $70 \mathrm{ppb}$, and 13 to $82 \mu \mathrm{g} \cdot \mathrm{m}^{-3}$, respectively. Daily mean ozone concentrations were in a similar range in summer and winter, with values from near zero to $32 \mathrm{ppb}$. There were usually very low ozone concentrations at night due to chemical loss, with the $\mathrm{NO}_{X}$ concentrations showing reciprocal variations between $\mathrm{NO}_{2}$ and ozone.

The levels of air pollutants (except $\mathrm{PM}_{2.5}$ ) differed noticeably in each of the adjacent micro-environments. However, the daily variations of primary pollutants $\left(\mathrm{CO}\right.$ and $\left.\mathrm{NO}_{2}\right)$ and $\mathrm{O}_{3}$ in each micro-built environment were similar to those recorded by the AQMS, where the direct emissions had a less significant impact. This implies that even with different emission strengths, the daily variations of pollutant levels in all micro-environments were controlled by larger-scale (regional) meteorological conditions in both monitoring periods (Figure 5), and the relative pollutant concentrations were influenced by local emissions from the adjacent roadways.

\subsubsection{Diurnal Variations}

Summertime diurnal variations on weekdays showed distinct bimodal distributions for $\mathrm{CO}$ and $\mathrm{NO}_{2}$, with clear differences in pollutant concentrations among the different micro-environments (Figure 6a,b). This is a typical pattern of primary traffic-related pollutants in urban areas due to the effects of morning and evening commuting under relatively stable atmospheric conditions. In this region, daytime traffic rates were not noticeably different from those observed during commuting periods. Therefore, the reduced daytime concentrations of primary pollutants were likely caused by more effective dilution processes due to the increased boundary layer height and more intense turbulence. The $\mathrm{O}_{3}$ concentration peaked at 13:30 due to photochemical production, with a secondary peak at 17:00 that was likely due to the advection of a large ozone plume from upwind urban regions. The concentration differences in diurnal variations of $\mathrm{CO}, \mathrm{NO}_{2}$, and $\mathrm{O}_{3}$ among the micro-built environments displayed similar patterns. The concentration differences among the monitoring sub-sites were minimal at night due to there being little traffic but became larger during the morning peak and reached a maximum in the late afternoon due to the different local traffic volumes at each sub-site, followed by rapid dilution of local traffic emissions. The diurnal variations of $\mathrm{PM}_{2.5}$ were almost identical among the different micro-environments, implying that local (on-site) traffic emissions were not a determining factor of local $\mathrm{PM}_{2.5}$ levels. However, $\mathrm{PM}_{2.5}$ also displayed a bimodal distribution, with a primary morning commuting period peak $\left(\sim 6 \mu \mathrm{g} \cdot \mathrm{m}^{-3}\right.$ elevation) and a smaller nighttime peak $\left(\sim 4 \mu \mathrm{g} \cdot \mathrm{m}^{-3}\right.$ elevation). Thus, it appears that $\mathrm{PM}_{2.5}$ was influenced by traffic activities over a larger spatial scale than the monitoring domain. 

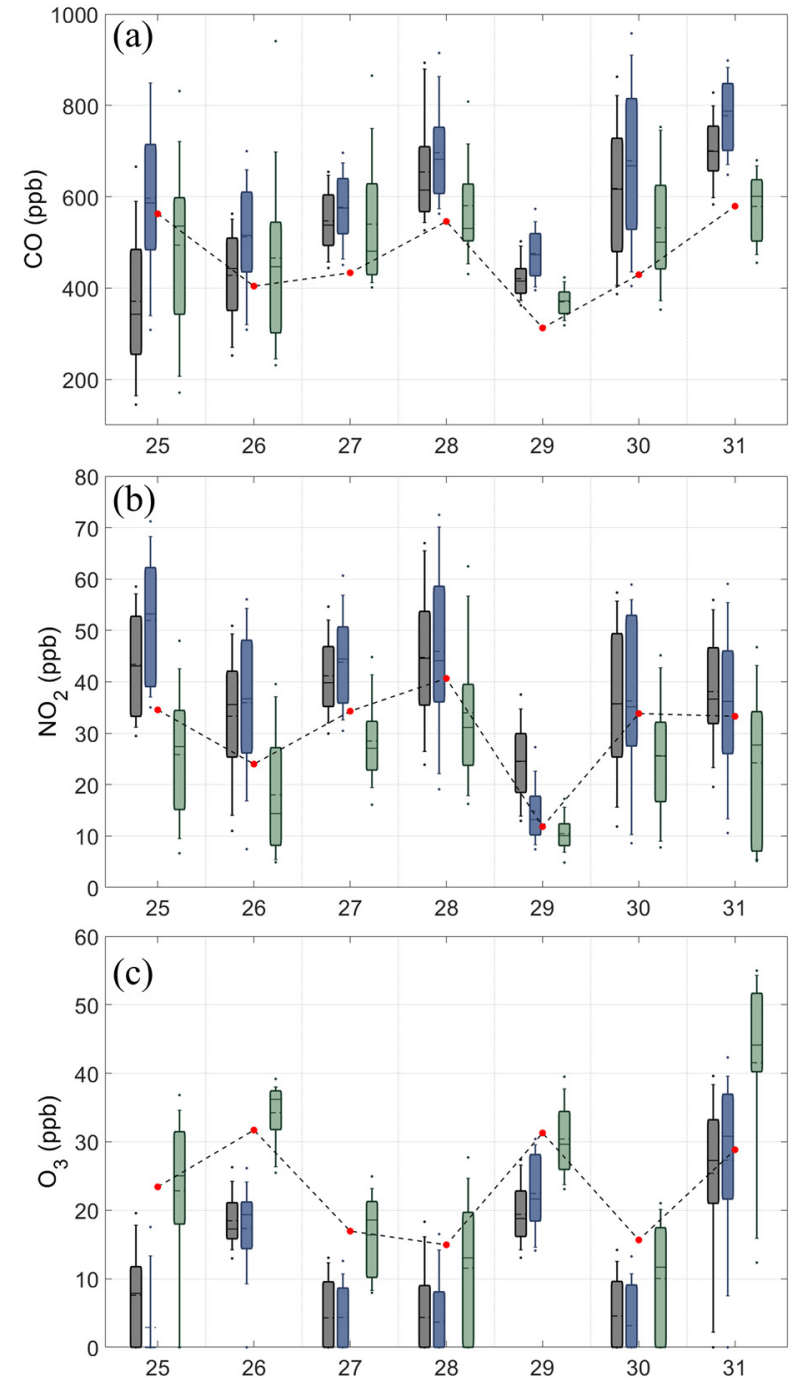

$25(d)$

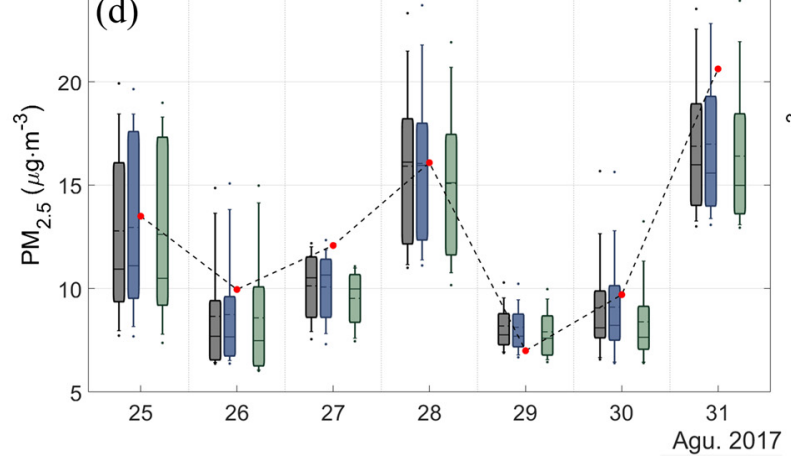

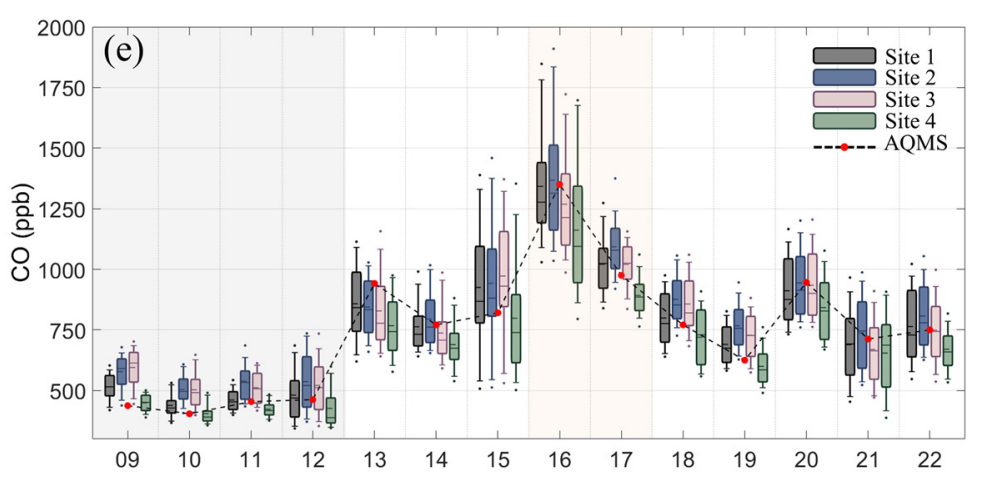
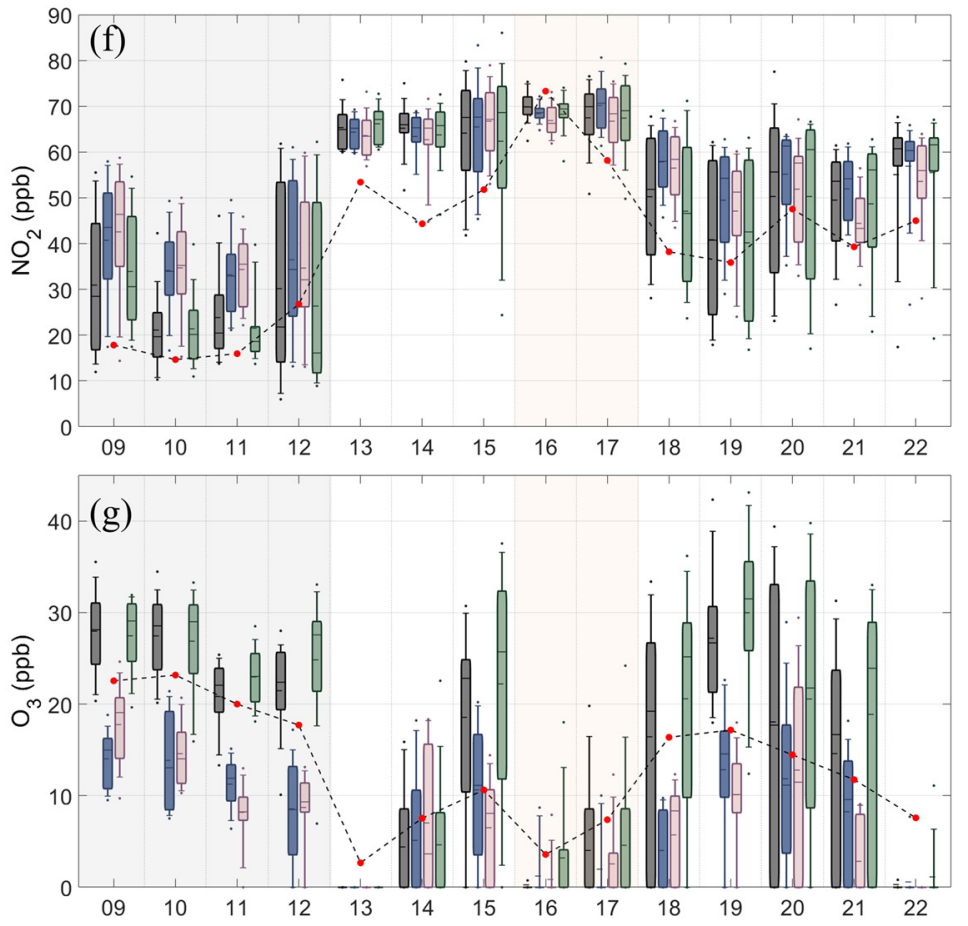

100 (h)

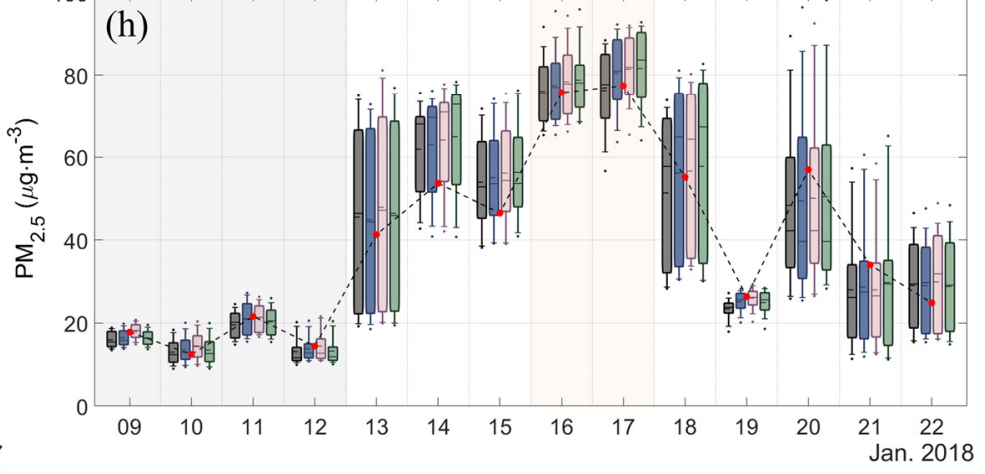

Figure 5. Box plots of the daily variations in air pollutants at each sub-site (dark gray: Site-1, dark blue: Site-2, pink: Site-3, and green: Site-4). The horizontal dashed lines in the box denote the mean values. Dotted lines with red dots represent the daily mean concentrations from the AQMS. The left panel (a-d) shows the daily variations for the summer period, and the right panel (e-h) shows those for the winter. The gray shaded area in winter represents the cold wave period, and the red shaded area represents the high $\mathrm{PM}_{2.5}$ event. Ozone data were used only for the period 11:00-17:00 because of the near-zero concentrations during the night. 
Summer
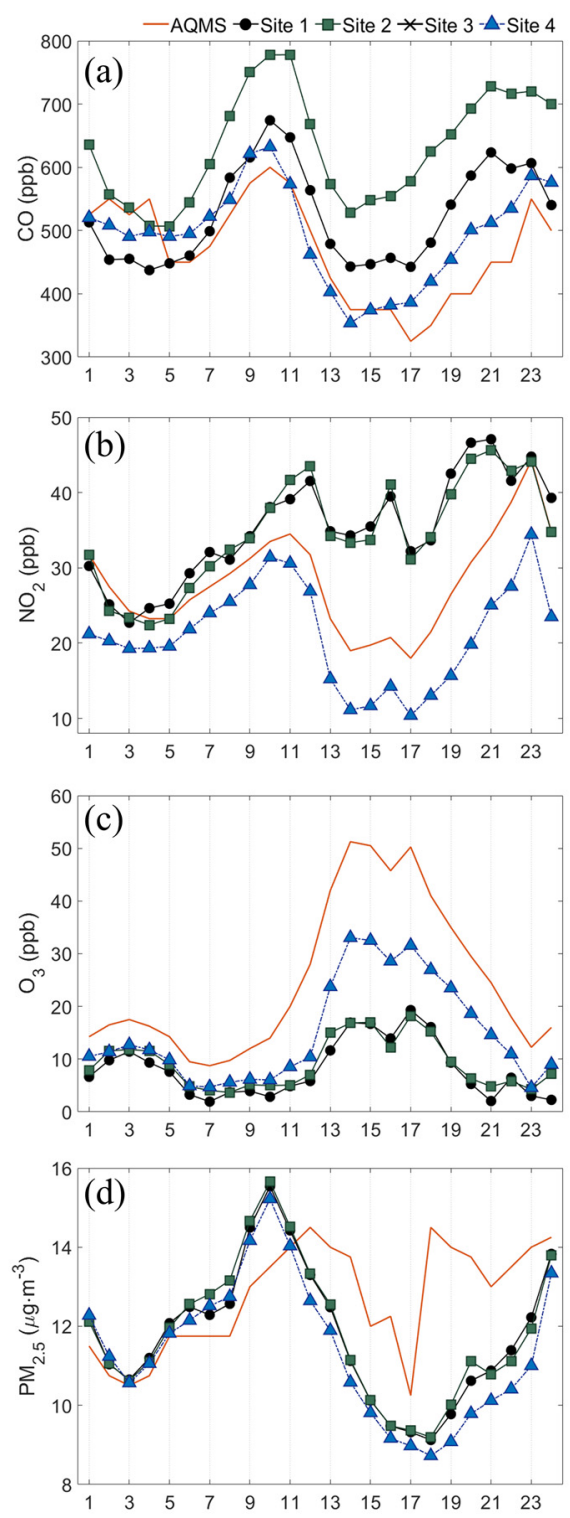

Winter
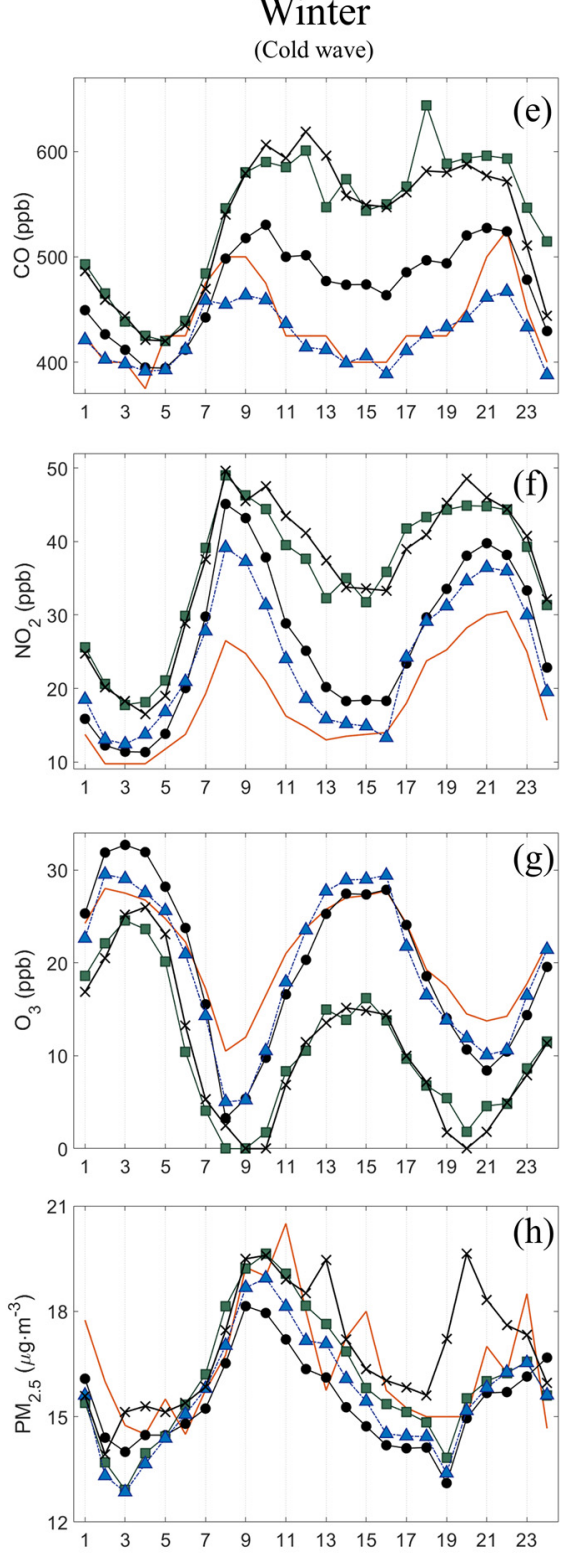

(g)
Winter
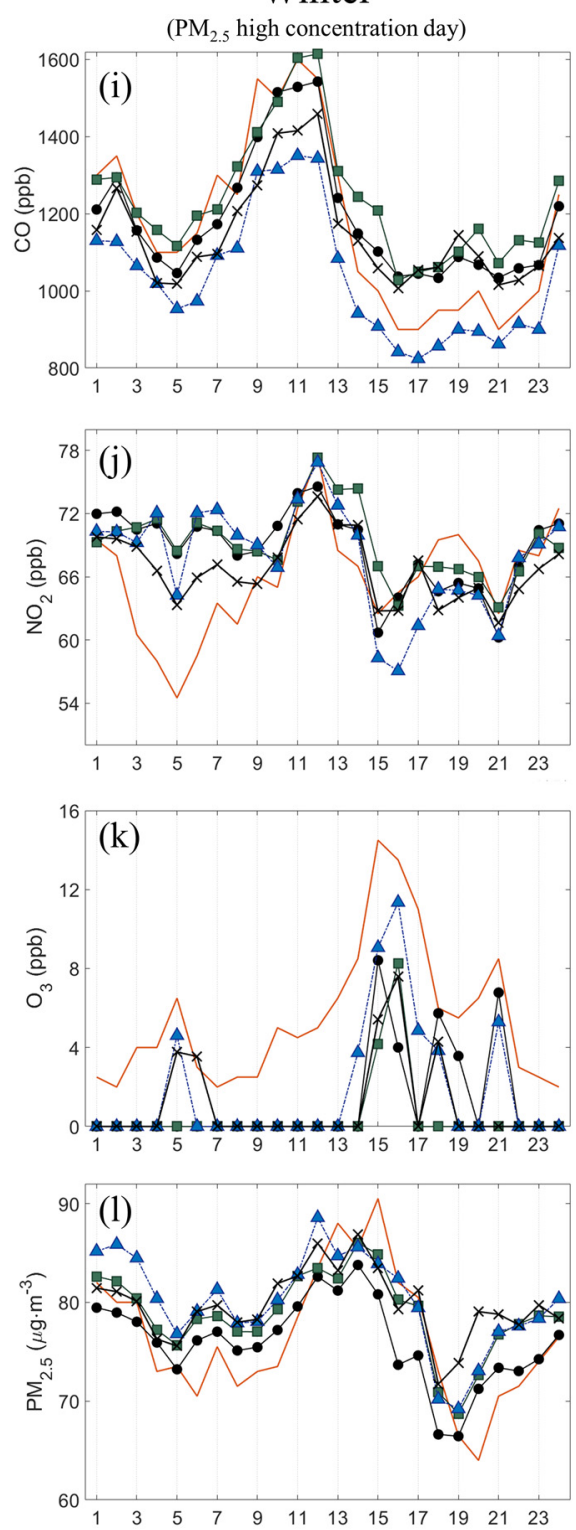

Figure 6. Weekday diurnal variations of air pollutants at each sub-site (black circles: Site-1, green squares: Site-2, black x: Site-3, blue triangles: Site-4, and orange line: the AQMS). The left panel shows the diurnal variations in summer (a-d), the middle panel shows the cold wave period $(\mathbf{e}-\mathbf{h})$, and the right panel shows the $\mathrm{PM}_{2.5}$ pollution event in winter (i-1).

In winter, there were two distinct weather patterns (a cold wave period with strong winds and a severe $\mathrm{PM}_{2.5}$ pollution period). Separate diurnal profiles were obtained for the two periods (Figure $6 \mathrm{c}-\mathrm{h}$ for the cold wave and Figure $6 \mathrm{i}-\mathrm{l}$ for $\mathrm{PM}_{2.5}$ pollution). During the cold wave period, $\mathrm{CO}$ and $\mathrm{NO}_{2}$ displayed typical bimodal variations, and the concentration differences between micro-environments were larger during daytime, similar to the summer pattern. Ozone displayed bimodal variation, and the nighttime peak was likely due to low levels of $\mathrm{NO}$ (as shown by the minimal $\mathrm{NO}_{2}$ concentrations), and the sharp decrease in the morning commute period was caused by enhanced NO emissions under the undeveloped boundary layer conditions. The $\mathrm{PM}_{2.5}$ concentration also had a similar diurnal pattern to that of summer, with a $\sim 4 \mu \mathrm{g} \cdot \mathrm{m}^{-3}$ elevation during the morning commuting period; no concentration differences between micro-environments were observed.

During the severe $\mathrm{PM}_{2.5}$ pollution period, the levels of all pollutants $\left(\mathrm{CO}, \mathrm{NO}_{2}\right.$, and $\mathrm{PM}_{2.5}$ ) were significantly higher than during other periods. The differences in pollutant 
levels among the micro-environments were insignificant compared to those for other monitoring periods (quantitative results are shown in Section 3.4.3), implying that this event occurred at a regional scale and the effects of local emissions from each microenvironment were masked by regional-scale variations. Ozone concentrations remained low ( $<10 \mathrm{ppb}$ even in the early afternoon) for the whole day, implying an accumulation of $\mathrm{NO}$ over this area.

\subsection{Spatial Variations of Air Pollutants}

3.4.1. Differences between Pollutant Concentrations at the Roadside and the On-Site AQMS

The sub-sites were located approximately $100-400 \mathrm{~m}$ apart, so the differences in pollutant concentrations between sites could be attributed to the local traffic and built environments under common meteorological conditions. We considered the relative difference (RD) in air pollutant concentrations between the monitoring sub-sites and AQMS placed on the roof of a 4-story building ( $\sim 15 \mathrm{~m}$ a.g.l.) at Site-4 ( $\sim 30 \mathrm{~m}$ from a single-lane road) (Figure 1). In summer, the $\mathrm{RD}$ varied significantly at each sub-site, but $\mathrm{CO}$ concentrations were generally $12-37 \%$ higher at the roadside sites compared to the AQMS values, indicating an impact of traffic emissions (Table 3). Daytime ground-level ozone was, however, significantly lower at all monitoring sub-sites (including Site-4) than at the AQMS, implying the importance of the chemical loss of ground-level ozone by freshly emitted $\mathrm{NO}$ (NO-titration effect). The relative elevation of $\mathrm{CO}$ and depletion of $\mathrm{O}_{3}$ at the roadside locations was more prominent at highly trafficked sites (Sites-1 and 2) than at Site-4, where the traffic flow was minimal. As with $\mathrm{CO}$, the $\mathrm{NO}_{2}$ concentrations at Site- 1 and Site- 2 were higher than at the AQMS, but the concentrations at Site- 4 were lower than at the AQMS, likely due to the conversion of $\mathrm{NO}$ to $\mathrm{NO}_{2}$ by $\mathrm{O}_{3}$ or the transport of $\mathrm{NO}_{2}$-rich plumes from adjacent roadways to the AQMS. The RD in $\mathrm{PM}_{2.5}$ was small at all sites, and the AQMS concentrations were slightly higher $(3-7 \%)$ than at ground level on average, implying the dominance of the secondary formation of $\mathrm{PM}_{2.5}$ in summer. However, considering the uncertainty of the sensors, we cannot exclude the possibility that these small differences in $\mathrm{PM}_{2.5}$ might have been caused by errors in the instrumental methods.

Table 3. Mean relative differences in concentrations at each sub-site with respect to the AQMS data (\%) ${ }^{1}$ (ozone data were used only for the period of 11:00-17:00 because of the near-zero roadside concentrations during the night).

\begin{tabular}{|c|c|c|c|c|c|c|}
\hline & & \multicolumn{4}{|c|}{$\begin{array}{l}\text { Relative Differences in Concentrations } \\
\text { (Standard Deviation }(1 \sigma) \text { in Parenthesis) }\end{array}$} & \multirow[t]{2}{*}{ Avg. AQMS Conc. $(1 \sigma)$} \\
\hline & & Site-1 & Site-2 & Site-3 & Site-4 & \\
\hline \multirow{4}{*}{ Summer } & $\mathrm{CO}$ & $19.0(29.8)$ & $37.3(27.7)$ & / & $11.9(24.4)$ & $469.8(174.2)$ \\
\hline & $\mathrm{NO}_{2}$ & $43.7(61.5)$ & $33.6(50.9)$ & / & $-20.8(23.2)$ & $28.1(15.3)$ \\
\hline & $\mathrm{O}_{3}$ & $-77.9(19.9)$ & $-77.7(23.7)$ & / & $-48.4(25.7)$ & $24.9(19.4)$ \\
\hline & $\mathrm{PM}_{2.5}$ & $-3.1(23.7)$ & $-2.9(23.3)$ & / & $-6.9(23.3)$ & $12.7(6.0)$ \\
\hline \multirow{4}{*}{$\begin{array}{l}\text { Winter } \\
\text { (Cold- } \\
\text { wave) }\end{array}$} & $\mathrm{CO}$ & $9.2(13.2)$ & $24.4(18.4)$ & $23.1(20.1)$ & $-1.9(9.4)$ & $429.2(68.3)$ \\
\hline & $\mathrm{NO}_{2}$ & $42.9(36.7)$ & $111.5(56.9)$ & $115.1(68.4)$ & $32.3(31.9)$ & $15.3(4.5)$ \\
\hline & $\mathrm{O}_{3}$ & $-5.4(12.4)$ & $-51.2(11.4)$ & $-52.4(16.3)$ & $0.7(9.9)$ & $21.6(5.4)$ \\
\hline & $\mathrm{PM}_{2.5}$ & $-4.6(12.9)$ & $1.9(13.0)$ & $6.8(15.9)$ & $-0.8(13.3)$ & $17.0(6.0)$ \\
\hline Winter & $\mathrm{CO}$ & $3.5(10.7)$ & $8.2(11.6)$ & $0.8(12.7)$ & $-10.6(5.1)$ & $1170(337.7)$ \\
\hline$\left(\mathrm{PM}_{2.5}\right.$ & $\mathrm{NO}_{2}$ & $6.5(18.3)$ & $7.7(19.3)$ & $3.8(18.0)$ & $5.2(18.5)$ & $65.9(10.5)$ \\
\hline pollution & $\mathrm{O}_{3}$ & $-90.7(23.3)$ & $-88.6(23.5)$ & $-88.5(23.0)$ & $-72.0(39.5)$ & $5.5(4.7)$ \\
\hline period) & $\mathrm{PM}_{2.5}$ & $-0.006(8.0)$ & $3.6(7.4)$ & $5.0(9.2)$ & $5.5(8.0)$ & $76.5(11.1)$ \\
\hline
\end{tabular}

For the cold wave period in winter, the RD values of air pollutant concentrations between each monitoring sub-site and the AQMS were remarkably different from those in the polluted period (Table 3). For the cold wave period (clean air), the RD of $\mathrm{CO}$ at each sub-site was similar to the value in the summer, with only slightly lower values $(-2-24 \%)$. The $\mathrm{RD}$ of $\mathrm{NO}_{2}$ was much higher at Site-2 and Site-3 than in summer (112-115\% vs. $34 \%$ ). 
The $\mathrm{RD}$ values for $\mathrm{NO}_{2}$ at Site- 1 and Site-4 (32-43\%) were similar to the value in summer at Site-1 (44\%). In addition, the RD of ozone was significantly decreased at all sites. These differences were a consequence of the lower $\mathrm{NO}_{2}$ and $\mathrm{O}_{3}$ concentrations at the AQMS, with similar levels at each sub-site compared to those in the summer. The AQMS was located on the roof of the building at Site- 4 (with minimal traffic) and was therefore not likely to be directly affected by local traffic emissions. The stronger prevailing and ground-level winds for the cold wave period (Figure 3) might enhance the ventilation and eddy diffusion efficiency, decreasing urban background $\mathrm{NO}_{X}$ concentrations. The reduced wintertime solar radiation weakened ozone production, lowering the urban background ozone concentration. However, these effects were relatively minor at roadside locations due to the direct impacts of traffic emissions, resulting in a larger RD in micro-environments with strong traffic emission impacts.

However, for the polluted period in winter, ground-level $\mathrm{CO}$ and $\mathrm{NO}_{2}$ concentrations at each sub-site were slightly higher than at the AQMS, with a significantly reduced RD (Table 3). Wintertime pollution events in Korea are linked to stagnant synoptic meteorological conditions [28], and occur at a regional scale, potentially masking local emission effects. The RD of daytime ozone was similar to that in summer at all sub-sites but given that the mean concentration at the AQMS was only $5.5 \mathrm{ppb}$, these differences were negligible. The RD of $\mathrm{PM}_{2.5}$ in winter was also insignificant at all sub-sites for both the cold wave and polluted periods. These results suggest that the spatial distributions of $\mathrm{PM}_{2.5}$ were homogeneous regardless of the season, at least within the monitoring spatial scale $(\sim 1 \times 1 \mathrm{~km})$, even in urban areas with a dense traffic network and various different micro-environments.

\subsubsection{Vertical Distribution of Air Pollutants}

The vertical distributions of air pollutants in the summer and winter periods are shown in Figure 7 (cold wave and polluted periods are displayed separately). Vertical differences in pollutant concentrations were more distinct in summer than winter. However, the vertical differences were smaller than the horizontal ground-level differences among the sub-sites. In summer, there was a more obvious elevation in the ground level $\mathrm{NO}_{2}$ concentration $(69.9 \%$ higher relative to $132 \mathrm{~m})$ than the ground level $\mathrm{CO}$ concentration (11.4\% higher relative to $132 \mathrm{~m}$ ), likely due to the higher urban background concentrations of $\mathrm{CO}$ relative to traffic emission impacts. Consistent with the $\mathrm{NO}_{2}$ distribution, the ozone concentration was lower at ground level, indicating that the ozone concentration in the urban center was locally controlled by $\mathrm{NO}_{X}$ emissions from traffic. There were slight vertical differences in mean $\mathrm{PM}_{2.5}$ concentrations, but the upper $75 \%$ and $90 \%$ concentrations clearly increased as the altitude increased, implying that photochemical formation in the atmosphere dominated over the direct traffic emissions of $\mathrm{PM}_{2.5}$ in summer.

In the cold wave period, the vertical profiles of pollutants were the opposite of those in summer, however, the difference in concentration with altitude was less significant (Figure 7e-h). Ground-level CO was slightly higher than at greater heights, but the concentration at $132 \mathrm{~m}$ was higher than at $15 \mathrm{~m}$. The $\mathrm{NO}_{2}$ concentration was slightly higher at $132 \mathrm{~m}$. We could not fully explain the elevated upper-level $\mathrm{NO}_{2}$ concentrations with this experimental setup, but the ground level concentrations at this sub-site (Site-1) were lower than at other sub-sites, unlike the summer results, probably due to the more efficient ventilation (higher ground-level wind speeds) caused by persistent westerly prevailing winds during the cold wave period (as discussed in Section 3.1). The relatively high concentrations at $132 \mathrm{~m}$ for the primary pollutants $\left(\mathrm{CO}\right.$ and $\left.\mathrm{NO}_{2}\right)$, and lower concentrations for $\mathrm{O}_{3}$ and $\mathrm{PM}_{2.5}$ might be attributed to the transport of urban plumes around the monitoring domain under the restricted photochemistry and vertical mixing conditions in wintertime.

In the winter polluted period, the shape of the vertical profiles was similar to those in the cold wave period (Figure 7i-1), but with higher concentrations and slightly smaller differences (median differences of $5 \%,-1 \%$, and $6 \%$ for $\mathrm{CO}, \mathrm{NO}_{2}$, and $\mathrm{PM}_{2.5}$, respectively). Ozone was not detected in the whole column due to the very high $\mathrm{NO}_{\mathbf{X}}$ concentration. The high concentrations of primary pollutants at all monitoring heights indicated stagnant me- 
teorological conditions and the regional accumulation of pollutants over the greater Seoul metropolitan area. However, ground-level $\mathrm{PM}_{2.5}$ was slightly higher than the upper-level concentrations, implying that local traffic effects were added to the regionally produced and/or long-range transported $\mathrm{PM}_{2.5}$ in highly polluted periods [28].
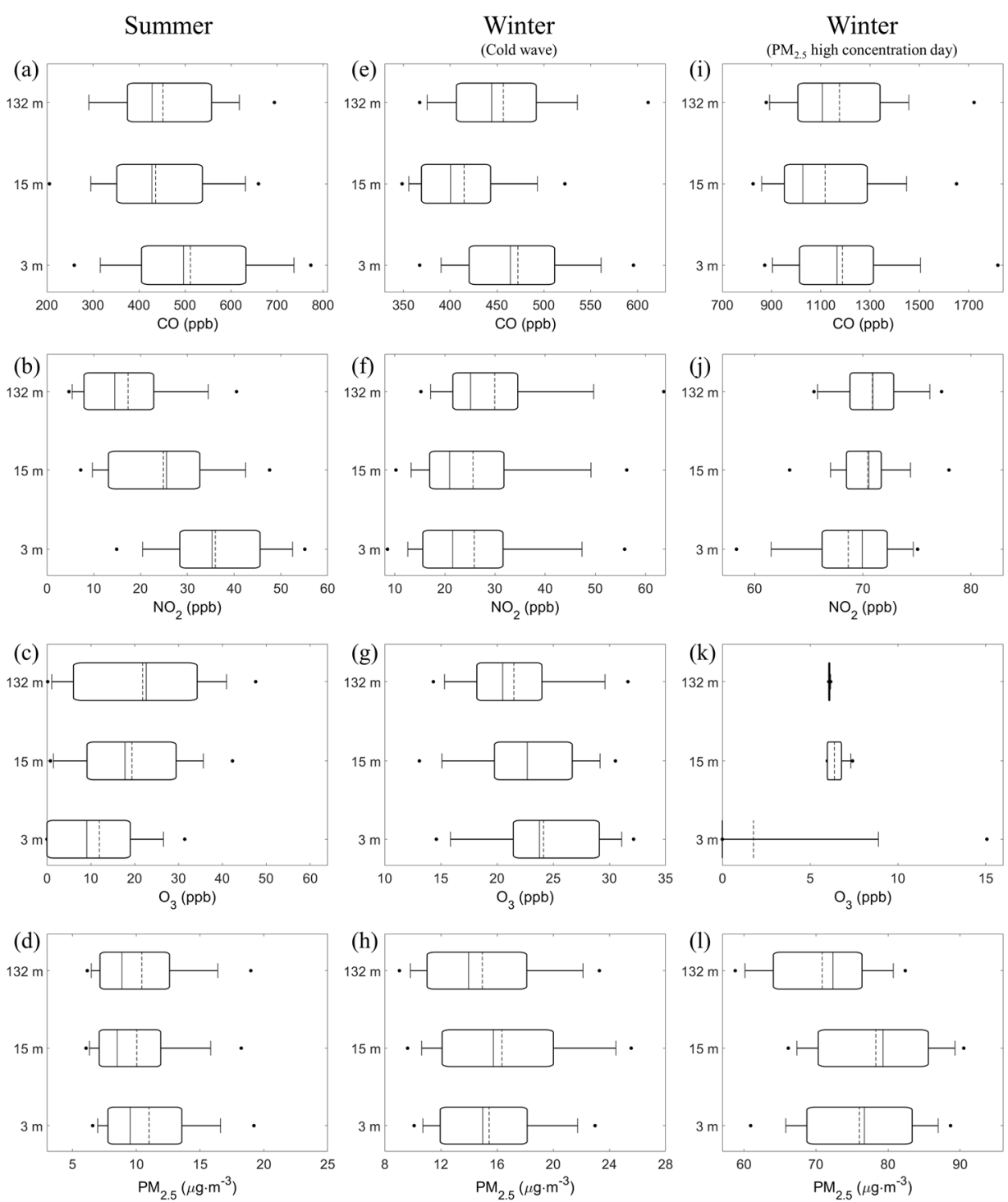

Figure 7. Horizontal box plots of the vertical distributions of pollutants at Site- 1 . The vertical dotted line in the box represents the mean value. $(\mathbf{a}-\mathbf{d})$ : summer, $(\mathbf{e}-\mathbf{h})$ : cold wave period of winter, and (i-1): the $\mathrm{PM}_{2.5}$ pollution event. Ozone data were used only for the period of 11:00-17:00.

\subsubsection{Spatial and Temporal Variability of Air Pollutants}

The concentrations of traffic-related air pollutants vary significantly in space and time due to the proximity of emission sources $[10,21,29]$. These spatial and temporal variations can be strongly affected by the surrounding built environment, surface meteorology within the urban-canopy, and emission strengths (e.g., traffic flow rates and fleet composition) [10]. Here, we define the spatial variability of pollutant levels among sub-sites as spatial heterogeneity and the spatial variability of temporal variations as temporal heterogeneity. To quantitatively determine the spatial and temporal heterogeneity of air pollutants in various micro-environments (Sites-1-4), two statistics were calculated: Pearson's correlation coefficient $(\mathrm{R})$ for temporal heterogeneity and the coefficient of divergence (COD) for spatial heterogeneity. 
The COD is widely used as a measure of spatial heterogeneity between a pair of simultaneously obtained time-series (Equation (1)) [30-32].

$$
\mathrm{COD}=\sqrt{\frac{1}{n} \sum_{i=1}^{n}\left(\frac{x_{i f}-x_{i h}}{x_{i f}+x_{i h}}\right)^{2}},
$$

where $n$ is the number of data points, $f$ and $h$ are the two observation sites to be compared, and $x$ is the concentration. A COD value of zero means that the two time-series are perfectly homogeneous, and a COD value $>0.2$ indicates a spatially heterogeneous distribution [31,32].

To simultaneously probe the extent of spatial and temporal heterogeneity in air pollutant distributions at each sub-site, we plotted COD vs. R for all sensor locations with respect to the location of sensor-node nearest to AQMS at Site-4 (Figures 1 and S1) where the traffic was minimal (Figure 8). In the plot, the upper left quadrant (I) represents spatially and temporally heterogeneous distributions, the upper right quadrant (II) represents spatially heterogeneous but temporally homogeneous distributions, and the lower right quadrant (IV) represents spatially and temporally homogeneous distributions. For temporal heterogeneity, we arbitrarily chose the criterion value of $\mathrm{R}=0.7$ (corresponding to an $\mathrm{R}^{2}$ value of $\sim 0.5$ ). Generally, $\mathrm{O}_{3}$ and $\mathrm{NO}_{2}$ displayed the largest spatial and temporal heterogeneity among the sub-sites, followed by $\mathrm{CO}$. This heterogeneity was enhanced during daytime when traffic activity was high compared to the nighttime, as reflected in the diurnal variations (Section 3.3.2), whereas $\mathrm{PM}_{2.5}$ had a homogeneous distribution within the monitoring domain in the summer (Figure 8a).

These large variabilities were significantly reduced in winter (Figure 8a vs. Figure 8b). However, when the cold wave period was examined separately, $\mathrm{NO}_{2}$ and $\mathrm{O}_{3}$ still had spatially heterogeneous distributions in the daytime (with a reduced extent compared to the summer period), but the nighttime spatial and temporal distributions were homogeneous due to the lower traffic emissions. The spatial and temporal distributions for $\mathrm{PM}_{2.5}$ were homogeneous and similar to those of the summer period. For the polluted period, all pollutants displayed homogeneous distributions in time and space within the domain (COD $<0.2$ or close to 0.2 for ozone; $\mathrm{R} \geq 0.7$ except for nighttime $\mathrm{NO}_{2}$ ), implying that the pollution event occurred at a much larger scale than this monitoring domain. The $\mathrm{NO}_{2}$ was distributed homogeneously in space $(\mathrm{COD}<0.1)$ but the temporal homogeneity was somewhat weak, most likely because concentrations were maintained at a high level over the polluted period.

Consequently, traffic-related pollutants displayed considerable variability in time and space even within the $800 \times 800 \mathrm{~m}$ domain, and spatiotemporal variability was enhanced during the daytime when people were more active outdoors. This variability was largest for pollutants emitted directly from roadways, with low background concentrations like $\mathrm{NO}_{\mathrm{X}}$. The large variability for ozone was most likely caused by the variability in $\mathrm{NO}_{\mathrm{X}}$ distributions due to the chemical loss caused by $\mathrm{NO}_{\mathrm{X}}$. The $\mathrm{PM}_{2.5}$ concentration was distributed homogeneously in time and space within the monitoring domain, implying that direct emissions from vehicles contributed much less to the $\mathrm{PM}_{2.5}$ mass concentrations compared to secondary production on a large spatial scale, unlike the particle number concentrations and elemental carbon (EC) $[10,29,30,33]$. 
(a) Summer
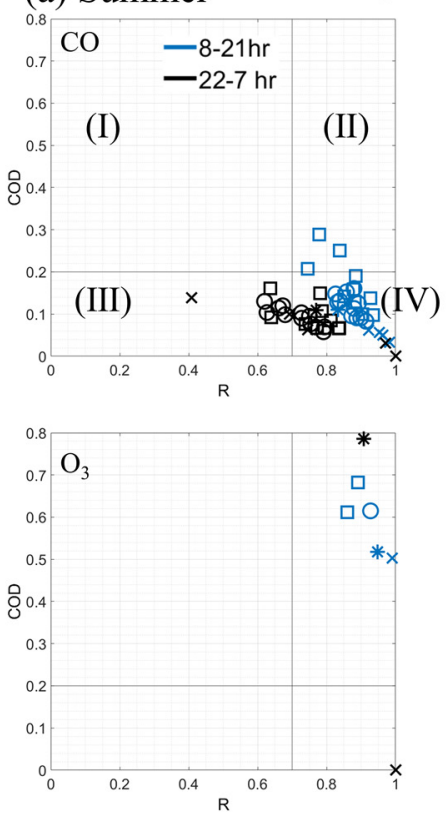

(c) Winter (cold wave)
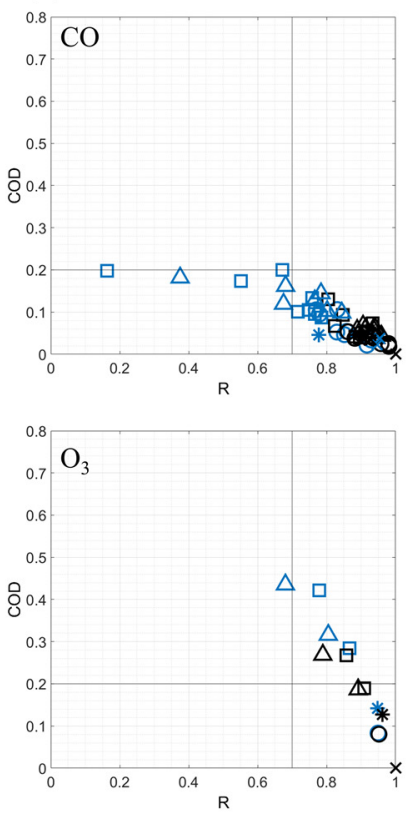

OSite $1 \square$ Site $2 \Delta$ Site $3 \times$ Site 4 * AQMS
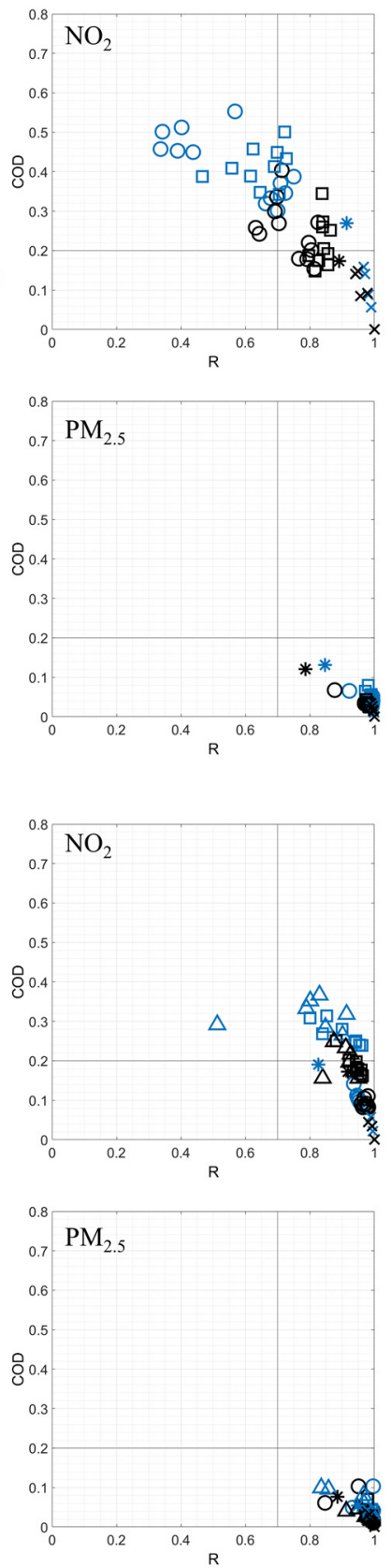

(b) Winter
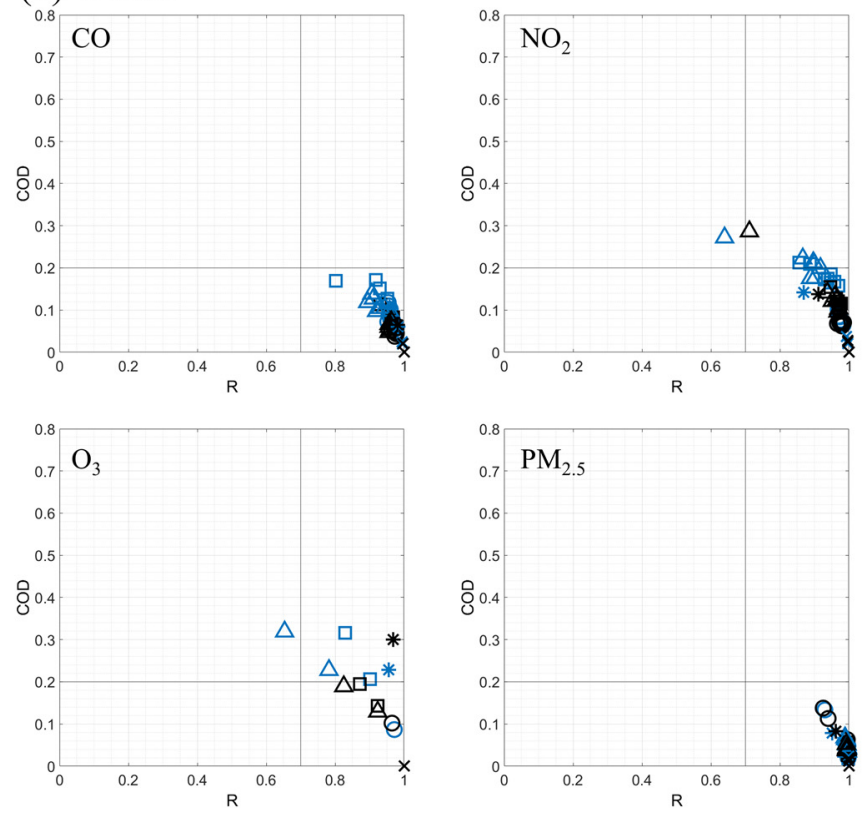

(d) Winter $\left(\mathrm{PM}_{2.5}\right.$ high concentration day)
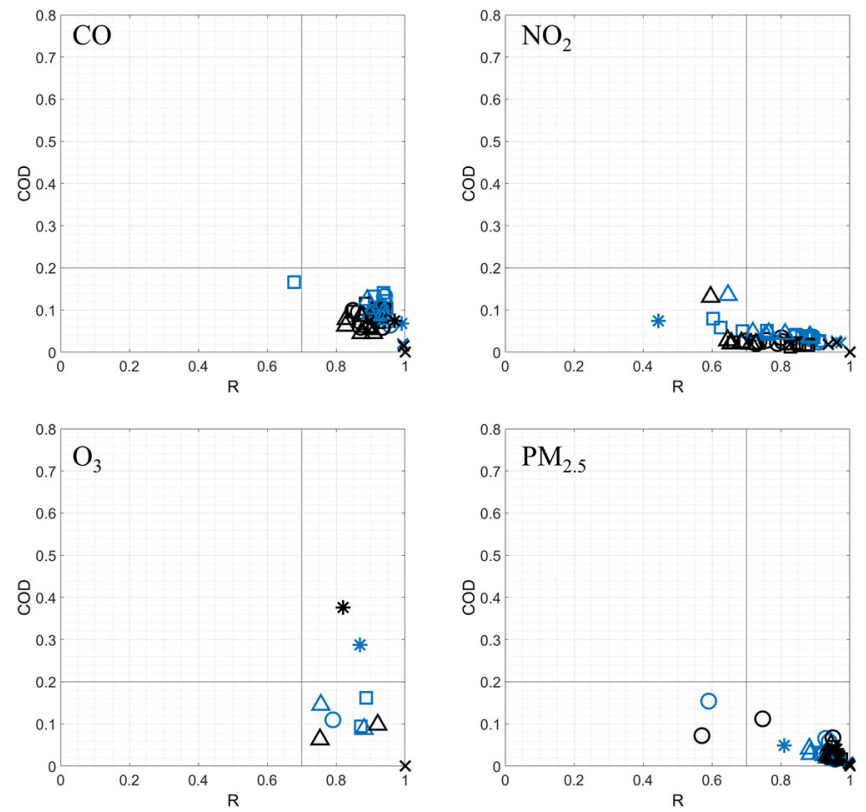

Figure 8. Plots of COD vs. R at each sensor-node location. Blue denotes daytime (08:00-21:00) and black represents nighttime (20:00-07:00). Circles denote the sensor-nodes located at Site-1, squares denote the sensor-nodes located at Site-2, triangles denote the sensor-nodes located at Site-3, x denote the sensor-nodes located at Site-4, and the asterisk indicates the AQMS. (I) represents a spatially and temporally heterogeneous distribution and (IV) represents a spatially and temporally homogeneous distribution.

\section{Conclusions}

Many studies have reported heterogeneous distributions of traffic-related air pollutants in urban areas, indicating the need for high-density air quality monitoring in areas where people are distributed $[19,34,35]$. To address this issue, a number of studies have suggested the potential for high-density air quality monitoring with cost-effective sensors. However, there have been few practical studies of high-density, cost-effective sensor networks in real urban environments. In this study, we deployed 30 sensor-nodes consisting of $\mathrm{CO}, \mathrm{NO}_{2}, \mathrm{O}_{3}$, and PM sensors in the center of Seoul, the largest megacity in South Korea, 
within an $800 \times 800 \mathrm{~m}$ monitoring domain, to investigate the spatial variability of the magnitude and temporal variations among various adjacent micro-environments. A sensor network was operated in summer and winter.

Daily variations in air pollutants at all sub-sites (micro-environments) had a similar temporal pattern, but the concentration levels differed between sub-sites and the AQMS operated by the government. These concentration differences (except $\mathrm{PM}_{2.5}$ ) were more pronounced in the daytime due to the higher traffic volumes. The weekday diurnal variation of air pollutants had a typical bimodal distribution, with morning and evening peaks for primary pollutants. The $\mathrm{PM}_{2.5}$ concentration also had a small morning peak, but the differences in concentration among sub-sites were nonsignificant. For the polluted period in winter, the diurnal variations displayed a different pattern, with nonsignificant differences in the concentrations among sub-sites.

Summertime ground-level concentrations of primary pollutants $\left(\mathrm{NO}_{2}\right.$ and $\left.\mathrm{CO}\right)$ were higher than the concentrations at upper levels, but the upper-level concentrations were higher for secondary pollutants $\left(\mathrm{O}_{3}\right.$ and $\left.\mathrm{PM}_{2.5}\right)$, as expected. This indicated that the nearby direct vehicular emissions of $\mathrm{PM}_{2.5}$ made an insignificant contribution to the $\mathrm{PM}_{2.5}$ mass concentration. However, in winter, these vertical distribution patterns were inversed, probably due to the large impact of urban plumes on a larger spatial scale under stable conditions at the upper level, in association with the more efficient ventilation at Site-1 on the ground.

We used a plot of COD vs. $R$ to quantitatively examine the spatial and temporal heterogeneity of air pollutants. The spatial and temporal variability was more significant in summer than winter. Among the pollutants, $\mathrm{NO}_{2}$ and $\mathrm{O}_{3}$ had the most significant spatial heterogeneity, followed by $\mathrm{CO} . \mathrm{PM}_{2.5}$ had homogeneous distributions. In the highly polluted period, temporal and spatial heterogeneity was minimal. These homogeneous spatiotemporal distributions, combined with the characteristics of the diurnal variations for the polluted period, suggest that the intensity and temporal variations of pollution events were determined on a larger spatial scale, while local emissions were masked. Ozone displayed the greatest spatial heterogeneity, with little temporal heterogeneity among the sub-sites and a negative correlation with $\mathrm{NO}_{2}$, implying that ozone concentrations were determined mainly by vehicular $\mathrm{NO}_{X}$ emissions due to $\mathrm{NO}$ titration effects under the urban canopy of the city.

The $\mathrm{PM}_{2.5}$ concentrations displayed homogeneous spatial and temporal distributions over the entire monitoring period within the monitoring domain, implying that $\mathrm{PM}_{2.5}$ monitoring with at least a $1 \times 1 \mathrm{~km}$ resolution is sufficient to examine the spatial variability of the magnitude and temporal variations of $\mathrm{PM}_{2.5}$ in urban areas. However, the other pollutants showed noticeable differences in daily and diurnal variations as well as spatial and temporal heterogeneity among different micro-environments within a $1 \times 1 \mathrm{~km}$ domain. Consequently, we think monitoring locations for traffic-related air pollutants other than $\mathrm{PM}_{2.5}$ should be determined based on traffic volume, surrounding built environments, and people's activities outdoors, rather than at a specific spatial resolution.

Supplementary Materials: The following are available online at https://www.mdpi.com/article/10 .3390/app11199105/s1, Figure S1: Configuration of sensor network, Figure S2: Examples of intercomparison results among sensor nodes obtained before and after the field experiments, Figure S3: Results of the comparison between AQMS vs. corrected and unadjusted sensor data, Figure S4: Time-series of wind speed, wind direction, and temperature, Table S1: Meteorology during the monitoring period.

Author Contributions: Conceptualization, Y.P. and W.C.; methodology, W.C., Y.P., J.-J.K. and S.-H.L.; validation, J.-Y.C., J.-B.L., S.-H.L. and J.-J.K.; formal analysis, Y.P.; investigation, Y.P., H.-S.P., S.H., K.H., S.L. and K.-H.K.; resources, J.-Y.C. and J.-B.L.; writing-original draft preparation, Y.P. and W.C.; writing-review and editing, J.-J.K., K.-H.K., S.-H.L., J.-Y.C. and J.-B.L.; visualization, Y.P. and S.H.; supervision, W.C.; project administration, W.C.; funding acquisition, S.-H.L. and J.-J.K. All authors have read and agreed to the published version of the manuscript. 
Funding: This work was supported by a grant from the National Institute of Environment Research (NIER) funded by the Ministry of Environment (MOE) of the Republic of Korea (NIER2021-01-02-069) and in part by the Technology Development Program to Solve Climate Changes through NRF (National Research Foundation of Korea) funded by the Ministry of Science and ICT (2019M1A2A2103954).

Institutional Review Board Statement: Not applicable.

Informed Consent Statement: Not applicable.

Data Availability Statement: Not applicable.

Conflicts of Interest: The authors declare no conflict of interest.

\section{References}

1. Krzyzanowski, M. Health Effects of Transport-Related Air Pollution: Summary for Policy-Makers; WHO Regional Office for Europe: Copenhagen, Denmark, 2005; ISBN 978-928-901-375-8.

2. CAPSS. National Air Pollutants Emission; National Institute of Environmental Research (NIER): Incheon, Korea, 2020. Available online: https: / / airemiss.nier.go.kr/user /boardList.do?comand=view\&page=1\&boardId=74\&boardSeq=579\&id=airemiss_04 0100000000 (accessed on 15 July 2021). (In Korean)

3. Baumgartner, J.; Zhang, Y.; Schauer, J.J.; Huang, W.; Wang, Y.; Ezzati, M. Highway proximity and black carbon from cookstoves as a risk factor for higher blood pressure in rural China. Proc. Natl. Acad. Sci. USA 2014, 111, 13229-13234. [CrossRef]

4. Brugge, D.; Durant, J.L.; Rioux, C. Near-highway pollutants in motor vehicle exhaust: A review of epidemiologic evidence of cardiac and pulmonary health risks. Environ. Health 2007, 6, 23. [CrossRef]

5. Wellenius, G.A.; Burger, M.R.; Coull, B.A.; Schwartz, J.; Suh, H.H.; Koutrakis, P.; Schlaug, G.; Gold, D.R.; Mittleman, M.A. Ambient Air Pollution and the Risk of Acute Ischemic Stroke. Arch. Intern. Med. 2012, 172, 229-234. [CrossRef]

6. United Nations. World Urbanization Prospects 2018; Department of Economic and Social Affairs, United Nations: New York, NY, USA, 2019.

7. Britter, R.E.; Hanna, S.R. Flow and dispersion in urban areas. Annu. Rev. Fluid Mech. 2003, 35, 469-496. [CrossRef]

8. Tan, Y.; Lipsky, E.M.; Saleh, R.; Robinson, A.L.; Presto, A.A. Characterizing the Spatial Variation of Air Pollutants and the Contributions of High Emitting Vehicles in Pittsburgh, PA. Environ. Sci. Technol. 2014, 48, 14186-14194. [CrossRef]

9. Vachon, G.; Louka, P.; Rosant, J.M.; Mestayer, P.G.; Sini, J.F. Measurements of Traffic-Induced Turbulence within a Street Canyon during the Nantes '99 Experiment. Water Air Soil Pollut. Focus 2002, 2, 127-140. [CrossRef]

10. Choi, W.; Ranasinghe, D.; Bunavage, K.; DeShazo, J.R.; Wu, L.; Seguel, R.; Winer, A.M.; Paulson, S.E. The effects of the built environment, traffic patterns, and micrometeorology on street level ultrafine particle concentrations at a block scale: Results from multiple urban sites. Sci. Total. Environ. 2016, 553, 474-485. [CrossRef]

11. Fu, X.; Liu, J.; Ban-Weiss, G.A.; Zhang, J.; Huang, X.; Ouyang, B.; Popoola, O.; Tao, S. Effects of canyon geometry on the distribution of traffic-related air pollution in a large urban area: Implications of a multi-canyon air pollution dispersion model. Atmos. Environ. 2017, 165, 111-121. [CrossRef]

12. Steffens, J.T.; Heist, D.K.; Perry, S.G.; Isakov, V.; Baldauf, R.W.; Zhang, K.M. Effects of roadway configurations on near-road air quality and the implications on roadway designs. Atmos. Environ. 2014, 94, 74-85. [CrossRef]

13. Pirjola, L.; Lähde, T.; Niemi, J.V.; Kousa, A.; Rönkkö, T.; Karjalainen, P.; Keskinen, J.; Frey, A.; Hillamo, R. Spatial and temporal characterization of traffic emissions in urban microenvironments with a mobile laboratory. Atmos. Environ. 2012, 63, 156-167. [CrossRef]

14. Woo, S.-H.; Kwak, K.-H.; Bae, G.-N.; Kim, K.H.; Kim, C.H.; Yook, S.-J.; Jeon, S.; Kwon, S.; Kim, J.; Lee, S.-B. Overestimation of on-road air quality surveying data measured with a mobile laboratory caused by exhaust plumes of a vehicle ahead in dense traffic areas. Environ. Pollut. 2016, 218, 1116-1127. [CrossRef] [PubMed]

15. Cheadle, L.; Deanes, L.; Sadighi, K.; Gordon Casey, J.; Collier-Oxandale, A.; Hannigan, M. Quantifying Neighborhood-Scale Spatial Variations of Ozone at Open Space and Urban Sites in Boulder, Colorado Using Low-Cost Sensor Technology. Sensors 2017, 17, 2072. [CrossRef] [PubMed]

16. Feinberg, S.N.; Williams, R.; Hagler, G.; Low, J.; Smith, L.; Brown, R.; Garver, D.; Davis, M.; Morton, M.; Schaefer, J.; et al. Examining spatiotemporal variability of urban particulate matter and application of high-time resolution data from a network of low-cost air pollution sensors. Atmos. Environ. 2019, 213, 579-584. [CrossRef] [PubMed]

17. Heimann, I.; Bright, V.B.; McLeod, M.W.; Mead, M.I.; Popoola, O.A.M.; Stewart, G.B.; Jones, R.L. Source attribution of air pollution by spatial scale separation using high spatial density networks of low cost air quality sensors. Atmos. Environ. 2015, 113, 10-19. [CrossRef]

18. Lung, S.-C.C.; Wang, W.-C.V.; Wen, T.-Y.J.; Liu, C.-H.; Hu, S.-C. A versatile low-cost sensing device for assessing PM 2.5 spatiotemporal variation and quantifying source contribution. Sci. Total. Environ. 2020, 716, 137-145. [CrossRef]

19. Mead, M.I.; Popoola, O.A.M.; Stewart, G.B.; Landshoff, P.; Calleja, M.; Hayes, M.; Baldovi, J.J.; McLeod, M.W.; Hodgson, T.F.; Dicks, J.; et al. The use of electrochemical sensors for monitoring urban air quality in low-cost, high-density networks. Atmos. Environ. 2013, 70, 186-203. [CrossRef] 
20. Mukherjee, A.; Brown, S.G.; McCarthy, M.C.; Pavlovic, N.R.; Stanton, L.G.; Snyder, J.L.; D’ Andrea, S.; Hafner, H.R. Measuring Spatial and Temporal PM2.5 Variations in Sacramento, California, Communities Using a Network of Low-Cost Sensors. Sensors 2019, 19, 4701. [CrossRef]

21. Karner, A.A.; Eisinger, D.S.; Niemeier, D.A. Near-Roadway Air Quality: Synthesizing the Findings from Real-World Data. Environ Sci. Technol. 2010, 44, 5334-5344. [CrossRef]

22. Kim, J.-J.; Baik, J.-J. A numerical study of the effects of ambient wind direction on flow and dispersion in urban street canyons using the RNG k- $\varepsilon$ turbulence model. Atmos. Environ. 2004, 38, 3039-3048. [CrossRef]

23. Park, H.-S.; Kim, R.-E.; Park, Y.-M.; Hwang, K.-C.; Lee, S.-H.; Kim, J.-J.; Choi, J.-Y.; Lee, D.-G.; Chang, L.-S.; Choi, W. The Potential of Commercial Sensors for Spatially Dense Short-term Air Quality Monitoring Based on Multiple Short-term Evaluations of 30 Sensor Nodes in Urban Areas in Korea. Aerosol Air Qual. Res. 2020, 20, 369-380. [CrossRef]

24. Urasinska-Wojcik, B.; Vincent, T.A.; Chowdhury, M.F.; Gardner, J.W. Ultrasensitive WO3 gas sensors for NO2 detection in air and low oxygen environment. Sens. Actuators B Chem. 2017, 239, 1051-1059. [CrossRef]

25. Zheng, T.; Bergin, M.H.; Johnson, K.K.; Tripathi, S.N.; Shirodkar, S.; Landis, M.S.; Sutaria, R.; Carlson, D.E. Field evaluation of low-cost particulate matter sensors in high- and low-concentration environments. Atmos. Meas. Tech. 2018, 11, 4823-4846. [CrossRef]

26. Kelly, K.E.; Whitaker, J.; Petty, A.; Widmer, C.; Dybwad, A.; Sleeth, D.; Martin, R.; Butterfield, A. Ambient and laboratory evaluation of a low-cost particulate matter sensor. Environ. Pollut. 2017, 221, 491-500. [CrossRef] [PubMed]

27. Peng, J.; Hu, M.; Shang, D.; Wu, Z.; Du, Z.; Tan, T.; Wang, Y.; Zhang, F.; Zhang, R. Explosive Secondary Aerosol Formation during Severe Haze in the North China Plain. Environ. Sci. Technol. 2021, 55, 2189-2207. [CrossRef] [PubMed]

28. Seo, J.; Lim, Y.B.; Youn, D.; Kim, J.Y.; Jin, H.C. Synergistic enhancement of urban haze by nitrate uptake into transported hygroscopic particles in the Asian continental outflow. Atmos. Chem. Phys. 2020, 20, 7575-7594. [CrossRef]

29. Ranasinghe, D.R.; Choi, W.; Winer, A.M.; Paulson, S.E. Developing High Spatial Resolution Concentration Maps Using Mobile Air Quality Measurements. Aerosol Air Qual. Res. 2016, 16, 1841-1853. [CrossRef]

30. Krudysz, M.A.; Froines, J.R.; Fine, P.M.; Sioutas, C. Intra-community spatial variation of size-fractionated PM mass, OC, EC, and trace elements in the Long Beach, CA area. Atmos. Environ. 2008, 42, 5374-5389. [CrossRef]

31. Moore, K.; Krudysz, M.; Pakbin, P.; Hudda, N.; Sioutas, C. Intra-Community Variability in Total Particle Number Concentrations in the San Pedro Harbor Area (Los Angeles, California). Aerosol Sci. Technol. 2009, 43, 587-603. [CrossRef]

32. Wilson, J.G.; Kingham, S.; Pearce, J.; Sturman, A.P. A review of intraurban variations in particulate air pollution: Implications for epidemiological research. Atmos. Environ. 2005, 39, 6444-6462. [CrossRef]

33. Choi, W.; Ranasinghe, D.; DeShazo, J.R.; Kim, J.-J.; Paulson, S.E. Where to locate transit stops: Cross-intersection profiles of ultrafine particles and implications for pedestrian exposure. Environ. Pollut. 2018, 233, 235-245. [CrossRef]

34. Kumar, P.; Morawska, L.; Martani, C.; Biskos, G.; Neophytou, M.; Di Sabatino, S.; Bell, M.; Norford, L.; Britter, R. The rise of low-cost sensing for managing air pollution in cities. Environ. Int. 2015, 75, 199-205. [CrossRef] [PubMed]

35. Vardoulakis, S.; Gonzalez-Flesca, N.; Fisher, B.E.A.; Pericleous, K. Spatial variability of air pollution in the vicinity of a permanent monitoring station in central Paris. Atmos. Environ. 2005, 39, 2725-2736. [CrossRef] 